\title{
Validation of MIPAS IMK/IAA temperature, water vapor, and ozone profiles with MOHAVE-2009 campaign measurements
}

\author{
G. P. Stiller ${ }^{1}$, M. Kiefer ${ }^{1}$, E. Eckert ${ }^{1}$, T. von Clarmann ${ }^{1}$, S. Kellmann ${ }^{1}$, M. García-Comas ${ }^{2}$, B. Funke ${ }^{2}$, T. Leblanc ${ }^{3}$,

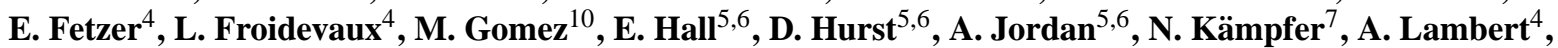 \\ I. S. McDermid ${ }^{3}$, T. McGee ${ }^{8}$, L. Miloshevich ${ }^{9}$, G. Nedoluha $^{10}$, W. Read $^{4}$, M. Schneider ${ }^{1}$, M. Schwartz ${ }^{4}$, C. Straub ${ }^{7}$, \\ G. Toon ${ }^{4}$, L. W. Twigg ${ }^{11}$, K. Walker ${ }^{12}$, and D. N. Whiteman ${ }^{8}$ \\ ${ }^{1}$ Karlsruhe Institute of Technology, Institute for Meteorology and Climate Research, Karlsruhe, Germany \\ ${ }^{2}$ Instituto de Astrofísica de Andalucía, CSIC, Granada, Spain \\ ${ }^{3}$ Caltech/Jet Propulsion Laboratory, Wrightwood, California, USA \\ ${ }^{4}$ Caltech/Jet Propulsion Laboratory, Pasadena, California, USA \\ ${ }^{5}$ NOAA Earth System Research Laboratory, Global Monitoring Division, Boulder, Colorado, USA \\ ${ }^{6}$ CIRES, University of Colorado, Boulder, Colorado, USA \\ ${ }^{7}$ Institute of Applied Physics, University of Bern, Bern, Switzerland \\ ${ }^{8}$ Laboratory for Atmospheres, Goddard Space Flight Center, Greenbelt, Maryland, USA \\ ${ }^{9}$ Milo Scientific LLC, Lafayette, Colorado, USA \\ ${ }^{10}$ Naval Research Laboratory, Washington, D.C., USA \\ ${ }^{11}$ Science Systems and Applications, Inc., Lanham, Maryland, USA \\ ${ }^{12}$ Department of Physics, University of Toronto, Ontario, Canada
}

Correspondence to: G. P. Stiller (gabriele.stiller@kit.edu)

Received: 21 April 2011 - Published in Atmos. Meas. Tech. Discuss.: 11 July 2011

Revised: 9 January 2012 - Accepted: 24 January 2012 - Published: 2 February 2012

\begin{abstract}
MIPAS observations of temperature, water vapor, and ozone in October 2009 as derived with the scientific level-2 processor run by Karlsruhe Institute of Technology (KIT), Institute for Meteorology and Climate Research (IMK) and CSIC, Instituto de Astrofísica de Andalucía (IAA) and retrieved from version 4.67 level-1b data have been compared to co-located field campaign observations obtained during the MOHAVE-2009 campaign at the Table Mountain Facility near Pasadena, California in October 2009. The MIPAS measurements were validated regarding any potential biases of the profiles, and with respect to their precision estimates. The MOHAVE-2009 measurement campaign provided measurements of atmospheric profiles of temperature, water vapor/relative humidity, and ozone from the ground to the mesosphere by a suite of instruments including radiosondes, ozonesondes, frost point hygrometers, lidars, microwave radiometers and Fourier transform infrared (FTIR) spectrometers. For MIPAS temperatures (version V4O_T_204), no significant bias was detected in the middle stratosphere; between $22 \mathrm{~km}$ and the tropopause MIPAS
\end{abstract}

temperatures were found to be biased low by up to $2 \mathrm{~K}$, while below the tropopause, they were found to be too high by the same amount. These findings confirm earlier comparisons of MIPAS temperatures to ECMWF data which revealed similar differences. Above $12 \mathrm{~km}$ up to $45 \mathrm{~km}$, MIPAS water vapor (version V4O_H2O_203) is well within $10 \%$ of the data of all correlative instruments. The well-known dry bias of MIPAS water vapor above $50 \mathrm{~km}$ due to neglect of non-LTE effects in the current retrievals has been confirmed. Some instruments indicate that MIPAS water vapor might be biased high by 20 to $40 \%$ around $10 \mathrm{~km}$ (or $5 \mathrm{~km}$ below the tropopause), but a consistent picture from all comparisons could not be derived. MIPAS ozone (version V4O_O3_202) has a high bias of up to +0.9 ppmv around $37 \mathrm{~km}$ which is due to a non-identified continuum like radiance contribution. No further significant biases have been detected. Cross-comparison to co-located observations of other satellite instruments (Aura/MLS, ACE-FTS, AIRS) is provided as well. 


\section{Introduction}

Altitude-resolved satellite measurements of atmospheric temperature, water vapor content and ozone mixing ratios are essential to obtain a global picture of the state of the atmosphere in the light of global change. One instrument providing such data is the Michelson Interferometer for Passive Atmospheric Sounding (MIPAS) (Fischer et al., 2008) onboard the Envisat research satellite. MIPAS is a mid-infrared limb emission Fourier transform spectrometer designed for global vertical profile measurement of temperature and many atmospheric trace constituents relevant to atmospheric chemistry and climate change. The measurement range of MIPAS extends from the upper troposphere to the lower thermosphere. MIPAS temperature measurements are a target result in their own right, because global altitude-resolved temperature information particularly in the upper stratosphere and above is limited. Beyond this, precise knowledge of temperatures is an essential precondition to trace gas retrievals, because the thermal emission of trace molecules depends strongly on temperature, and any temperature retrieval error will propagate onto the retrieved concentration profiles. Water vapor and ozone, also part of the MIPAS data product, are essential climate variables, contribute to the greenhouse effect of the atmosphere, are involved in atmospheric chemistry, and are tracers of atmospheric transport.

There exist multiple processors for analysis of MIPAS spectra; this paper focuses on temperature, water vapor and ozone profiles retrieved with the data processor operated by the Institute of Meteorology and Climate Research (IMK) at the Karlsruhe Institute of Technology (KIT) in cooperation with the Instituto de Astrofísica de Andalucía (von Clarmann et al., 2003b), which supports analysis of a greater variety of atmospheric species than the operational ESA processor (Ridolfi et al., 2000; Raspollini et al., 2006) and more observation modes with an extended altitude range. From summer 2002 to spring 2004, MIPAS measured in its original measurement mode at a spectral resolution of $0.025 \mathrm{~cm}^{-1}$ unapodized. Retrieval of temperature, water vapor and ozone profiles has been described by von Clarmann et al. (2003b), Milz et al. (2005), and Glatthor et al. (2005, 2006), respectively. The functionality of the retrieval processor and the underlying radiative transfer code KOPRA (Stiller et al., 2002) were validated by von Clarmann et al. (2003a,c, 2002), respectively. The resulting MIPAS data product was validated by Wang et al. $(2004,2005)$ for temperature, Milz et al. (2009) for water vapor and Steck et al. (2007) for ozone. After a failure of the interferometer slide in 2004, measurements at the original high spectral resolution were no longer possible, and from January 2005 on measurements in the new so-called optimized-resolution nominal observation mode were recorded at $0.0625 \mathrm{~cm}^{-1}$ unapodized. The retrieval scheme had to be adjusted to the new measurement mode (von Clarmann et al., 2009). This paper reports the first validation of these new data products, which took place within the framework of the MOHAVE-2009 campaign at Table Mountain (California) in October 2009 (Leblanc et al., 2011), where a multitude of in situ, lidar and remote sensing instruments provided coincident measurements.

\section{MIPAS data and retrieval}

MIPAS on Envisat provides in its optimized-resolution nominal observation mode about 1300 radiance profiles per day, each consisting of 27 radiance spectra covering the altitude range of 6 to $70 \mathrm{~km}$, and the spectral range of 4.15 to $14.6 \mu \mathrm{m}$. The sun-synchronous orbit of Envisat at approx. $800 \mathrm{~km}$ altitude allows coverage of the globe from pole to pole, with a horizontal sampling of $410 \mathrm{~km}$ along 14.4 orbits per day. The vertical sampling is $1.5 \mathrm{~km}$ up to $21 \mathrm{~km}$ altitude, $2 \mathrm{~km}$ up to $31 \mathrm{~km}$ altitude, $3 \mathrm{~km}$ up to $46 \mathrm{~km}$ altitude and $4 \mathrm{~km}$ above. The instantaneous vertical field-of-view covers $3 \mathrm{~km}$, i.e. oversampling is achieved in the troposphere and lower stratosphere. Due to its emission sounding capability, MIPAS records spectra of the atmosphere during day and night.

Retrieval of temperature and trace gases from the optimized-resolution nominal observation mode at IMK/IAA is described in von Clarmann et al. (2009). The retrieval is based on constrained inverse modelling of limb radiances. The IMK/IAA processor performs regularized retrievals on a finer altitude grid $(1 \mathrm{~km}$ gridwidth in the troposphere up to the middle stratosphere). Thus, stable solutions can only be obtained by regularization. While other MIPAS processors (Burgess et al., 2004, 2006; Hoffmann et al., 2008) regularize by the maximum a posteriori (also known as optimal estimation) method (Rodgers, 2000), the IMK/IAA processor uses a smoothing constraint, which operates by weighted minimization of the squared first order finite differences of adjacent profile values, using a Tikhonov (1963) formalism. The intent of this choice is to make the resulting profiles less dependent on the a priori profiles. For each target, dedicated spectral ranges, so-called microwindows, are used which were selected such that the total error consisting of measurement noise and parameter errors from the forward modeling is optimized.

For the retrieval targets analysed in this paper, i.e. temperature, water vapor and ozone, a detailed description of the specific retrieval approach, microwindows and the estimated precision, accuracy and vertical resolution for the current data versions (version V4O_T_204, version V4O_H2O_203, and version V4O_O3_202) is given in von Clarmann et al. (2009). A summary of the relevant numbers, i.e. vertical resolution, measurement noise error, total precision (including measurement noise and all parameter errors of random nature), total accuracy (including total precision and all systematic error sources), and horizontal resolution along the line-of-sight (in terms of full width at half maximum of the horizontal averaging kernel) is provided in Table 1. 
Table 1. Data and error chararacterization of temperature, water vapor, and ozone retrieved from MIPAS level-1b version 4.67 spectra (optimized-resolution nominal observation mode) at IMK/IAA.

\begin{tabular}{lrrr}
\hline $\begin{array}{l}\text { Retrieval } \\
\text { target }\end{array}$ & $\begin{array}{r}\text { Temperature } \\
\text { (version V4O_T_204) }\end{array}$ & $\begin{array}{r}\text { Water vapor } \\
\text { (version V4O_H2O_203) }\end{array}$ & $\begin{array}{r}\text { Ozone } \\
\text { (version V4O_O3_202) }\end{array}$ \\
\hline Vertical resolution & $\begin{array}{r}3.4 \mathrm{~km}(10 \mathrm{~km}) \text { to } \\
1.9 \mathrm{~km}(40 \mathrm{~km})\end{array}$ & $\begin{array}{r}2.3 \mathrm{~km}(20 \mathrm{~km}) \text { to } \\
6.9 \mathrm{~km}(50 \mathrm{~km})\end{array}$ & $\begin{array}{r}2.4 \mathrm{~km}(20 \mathrm{~km}) \text { to } \\
3.5 \mathrm{~km}(50 \mathrm{~km})\end{array}$ \\
Measurement noise & $0.2 \mathrm{~K}(10 \mathrm{~km})$ to & $0.13 \mathrm{ppmv}(10 \mathrm{~km})$ to & $\begin{array}{r}0.03 \mathrm{ppmv}(10 \mathrm{~km}) \text { to } \\
0.84 \mathrm{ppmv}(50 \mathrm{~km})\end{array}$ \\
Total precision & $0.8 \mathrm{~K}(50 \mathrm{~km})$ & $0.08 \mathrm{ppmv}(50 \mathrm{~km})$ \\
& $0.5 \mathrm{~K}(10 \mathrm{~km})$ to & $0.20 \mathrm{ppmv}(10 \mathrm{~km})$ to & $0.07 \mathrm{ppmv}(15 \mathrm{~km})$ to \\
Total accuracy & $1.4 \mathrm{~K}(50 \mathrm{~km})$ & $0.92 \mathrm{ppmv}(50 \mathrm{~km})$ & $0.28 \mathrm{ppmv}(40 \mathrm{~km})$ \\
& $0.5 \mathrm{~K}(10 \mathrm{~km})$ to & $0.34 \mathrm{ppmv}(10 \mathrm{~km})$ to & $0.07 \mathrm{ppmv}(10 \mathrm{~km})$ to \\
& $2.1 \mathrm{~K}(50 \mathrm{~km})$ & $1.06 \mathrm{ppmv}(35 \mathrm{~km})$ & $0.78 \mathrm{ppmv}(30 \mathrm{~km})$ \\
Horizontal resolution & $128 \mathrm{~km}(10 \mathrm{~km})$ to & $206 \mathrm{~km}(10 \mathrm{~km})$ to & $253 \mathrm{~km}(10 \mathrm{~km})$ to \\
& $402 \mathrm{~km}(40 \mathrm{~km})$ & $436 \mathrm{~km}(40 \mathrm{~km})$ & $405 \mathrm{~km}(40 \mathrm{~km})$ \\
\hline
\end{tabular}

Preliminary comparisons of the retrieved MIPAS temperatures with ECMWF temperature fields indicated that there might be a systematic retrieval problem in the subtropics $\left(25^{\circ}\right.$ to $40^{\circ} \mathrm{N} / \mathrm{S}$ ) below $\sim 22 \mathrm{~km}$ : MIPAS temperatures seemed to be systematically higher by up to $2 \mathrm{~K}$ below the tropopause and lower by up to $2 \mathrm{~K}$ between the tropopause and $\sim 22 \mathrm{~km}$. Since any temperature retrieval error will propagate onto the retrieved concentration profiles, a careful validation of temperatures is most important.

\section{MOHAVE-2009 campaign}

The Measurements of Humidity in the Atmosphere and Validation Experiments (MOHAVE) 2009 campaign took place at the JPL Table Mountain Facility (TMF) at $34.4^{\circ} \mathrm{N}$, $117.7^{\circ} \mathrm{W}$ on $11-27$ October 2009. MOHAVE-2009 was an extended version of the MOHAVE and MOHAVE-2 campaigns held at TMF in October 2006 and 2007. These campaigns, endorsed by the Network for the Detection of Atmospheric Composition Change (NDACC), allowed a thorough evaluation of the water vapor Raman lidar measurements up to the lower stratosphere by comparing to RS92 radiosonde and cryogenic frost point hygrometer profiles.

Though lidar validation had again triggered the planning of the campaign, many other instruments and techniques joined the intercomparison efforts, leading to one of the most extensive atmospheric water vapor validation campaigns ever performed. The main goal of the campaign was to validate the water vapor measurements of four Raman lidars, two microwave radiometers, two types of operational radiosondes, two types of frost point hygrometers, and an Infrared FourierTransform Spectrometer, as well as the column water measurements of a Ultra-Violet Fourier-Transform Spectrometer and two Global Positioning System (GPS) receivers. Measurements from five satellite instruments were included in the set of correlative data. Another goal of the campaign was to provide water vapor profiles from the ground to the mesopause without gaps. The third and last objective was to study water vapor variability in the UTLS in connection with the position of the subtropical jet near TMF.

MOHAVE-2009 not only hosted all the instruments of the earlier campaigns in 2006 and 2007, but included three additional instruments and/or techniques, leading to the correlative measurement of temperature and water vapor from the ground to the mesopause, and ozone from the ground to the stratopause. To optimize the lidar range, the core of the campaign was centered near 19 October at the occurrence of the new moon. Additional high priority nights (i.e. selected timing and increased density of the measurements and balloon launches) corresponded to the Aura Microwave Limb Sounder (MLS), Aura Tropospheric Emission Spectrometer (TES), Aqua Atmospheric Infrared Sounder (AIRS), Atmospheric Chemistry Experiment (ACE), and MIPAS best coincidences near TMF. The campaign operations were adjusted in real time following the most favorable atmospheric conditions. High-resolution potential vorticity (PV) analysis and forecasts from the MIMOSA transport model (Hauchecorne et al., 2002) supported the measurement planning. A more detailed description of the campaign operations and planning rationale is provided in the review paper by Leblanc et al. (2011).

\subsection{Operated instruments}

A detailed description of the measurement principles and instruments operated during MOHAVE-2009 is provided in the review paper by Leblanc et al. (2011), and the dedicated articles in the present special issue on the MOHAVE-2009 campaign (Hurst et al., 2011b; Leblanc et al., 2012a; Whiteman et al., 2011). Here we give only a short introduction to the instruments which have been used within the validation of MIPAS. A summary of the instruments' main characteristics in terms of vertical resolution and measurement total uncertainty as retrieved from the data files is provided in Table 2. 
Table 2. Summary of vertical resolutions und total uncertainties of coincident measurements. The total uncertainties are derived by averaging over all provided error profiles of a single type within 10-km altitude bins, after having transformed the original provided measured quantity and its error into $\mathrm{K}$ or volume mixing ratio. The range of these mean errors over all altitude bins is given in the table. Uncertainties not provided in the data files but taken from references cited in the text are given in bold face.

\begin{tabular}{|c|c|c|c|}
\hline Insrument & Measured quantity & Vertical Resolution & Uncertainty $[\mathrm{K}]$ or $[\%]$ \\
\hline \multirow[t]{4}{*}{ TMW/TMF lidar } & $\mathrm{H}_{2} \mathrm{O}[\mathrm{ppmv}]$ & $150 \mathrm{~m}$ up to a & $5.2-30 \%$ \\
\hline & $\mathrm{O}_{3}$ strat $\left[\mathrm{mol} \mathrm{m}^{-3}\right]$ & few kilometers & $11-28 \%$ \\
\hline & $\mathrm{O}_{3}$ trop $\left[\mathrm{mol} \mathrm{m}^{-3}\right]$ & & $5-13 \%$ \\
\hline & $T[\mathrm{~K}]$ & & $0.7-2.6 \mathrm{~K}$ \\
\hline \multirow{3}{*}{ STROZ lidar } & $\mathrm{H}_{2} \mathrm{O}\left[\mathrm{g} \mathrm{kg}^{-1}\right]$ & up to $1.5 \mathrm{~km}$ & $9 / 8 \%$ \\
\hline & $\mathrm{O}_{3}\left[\mathrm{~m}^{-3}\right]$ & & $0.7-19 \%$ \\
\hline & $T[\mathrm{~K}]$ & & $0.13-0.67 \mathrm{~K}$ \\
\hline \multirow{2}{*}{ ALVICE lidar } & $\mathrm{H}_{2} \mathrm{O}[\mathrm{ppmv}]$ & up to $1.2 \mathrm{~km}$ & $2.3-27 \%$ \\
\hline & $T[\mathrm{~K}]$ & & $0.18-0.33 \mathrm{~K}$ \\
\hline \multirow[t]{3}{*}{$\mathrm{CFH}^{1}$} & $\mathrm{H}_{2} \mathrm{O}[\mathrm{ppmv}]$ & meters & $7 \%$ \\
\hline & $\mathrm{O}_{3}[\mathrm{ppmv}]$ & & $5-10 \%$ \\
\hline & $T[\mathrm{C}]$ & & $0.5 \mathrm{~K}$ \\
\hline \multirow[t]{3}{*}{$\mathrm{NOAA} \mathrm{FPH}^{1}$} & $\mathrm{H}_{2} \mathrm{O}[\mathrm{ppmv}]$ & meters & $7 \%$ \\
\hline & $\mathrm{O}_{3}[\mathrm{ppmv}]$ & & $5-10 \%$ \\
\hline & $T[\mathrm{C}]$ & & $0.5 \mathrm{~K}$ \\
\hline RS92_GSFC & $T[\mathrm{C}]$ & meters & $0.5 \mathrm{~K}$ \\
\hline RS92_JPL & $T[\mathrm{C}]$ & meters & $0.5 \mathrm{~K}$ \\
\hline WVMS & $\mathrm{H}_{2} \mathrm{O}[\mathrm{ppmv}]$ & $12-15 \mathrm{~km}$ & $8 \%$ \\
\hline MIAWARA-C & $\mathrm{H}_{2} \mathrm{O}[\mathrm{ppmv}]$ & $12-15 \mathrm{~km}$ & $12-21 \%$ \\
\hline MkIV & $\mathrm{H}_{2} \mathrm{O}[\mathrm{ppmv}]$ & $3-6 \mathrm{~km}$ & $5 \%$ \\
\hline \multirow{3}{*}{ Aura/MLS } & $\mathrm{H}_{2} \mathrm{O}[p p m v]$ & $1.5-3 \mathrm{~km}$ & $5.7-22 \%$ \\
\hline & $\mathrm{O}_{3}[\mathrm{ppmv}]$ & & $1.6-60 \%$ \\
\hline & $T[\mathrm{~K}]$ & & $0.6-2.2 \mathrm{~K}$ \\
\hline \multirow[t]{3}{*}{ ACE-FTS } & $\mathrm{H}_{2} \mathrm{O}[\mathrm{ppmv}]$ & $3 \mathrm{~km}$ & $5.1-25 \%$ \\
\hline & $\mathrm{O}_{3}[\mathrm{ppmv}]$ & & $2.5-27 \%$ \\
\hline & $T[\mathrm{~K}]$ & & $2 \mathrm{~K}$ \\
\hline \multirow[t]{2}{*}{ AIRS } & $\mathrm{H}_{2} \mathrm{O}\left[\mathrm{g} \mathrm{kg}^{-1}\right]^{2}$ & $2-7 \mathrm{~km}$ & $18-21 \%$ \\
\hline & $T[\mathrm{~K}]$ & & $1.0-2.6 \mathrm{~K}$ \\
\hline
\end{tabular}

${ }^{1} \mathrm{~T}$ from radiosondes (RS92) and $\mathrm{O}_{3}$ from ozonesondes flown with the frost point hygrometers. ${ }^{2}$ All profiles with errors larger than $30 \%$ have been removed before comparison.

\subsubsection{Lidars}

The JPL water vapor Raman lidar at TMF (TMW) is a high-capability lidar system dedicated to the measurement of water vapor in the upper troposphere and lower stratosphere (Leblanc et al., 2008, 2012a). The light emitted by a $\mathrm{Nd}$ :YAG laser at $355 \mathrm{~nm}$ is inelastically backscattered by atmospheric nitrogen and water vapor, and collected at $387 \mathrm{~nm}$ and $407 \mathrm{~nm}$ respectively. After a few typical signal corrections (background correction (top end of the raw signals), saturation correction (non linearity at the bottom end of the signals), correction for molecular extinction along the laser beam path to the backscatter altitude and back), the ratio of the lidar signals collected in the water vapor and nitrogen channels is proportional to water vapor mixing ratio. The profiles are calibrated using external measurements, more specifically radiosondes during MOHAVE-2009. Systematic uncertainty is estimated to be 5-10\% mainly depending on the calibration accuracy. Precision is mostly driven by random noise (photon counting), and typically ranges for several hours of integration from under $0.5 \%$ in the mid-troposphere to $50 \%$ in the UTLS. To mitigate this noise, the profiles are vertically smoothed and the resulting resolution ranges from $150 \mathrm{~m}$ at the bottom to a few kilometers at $20 \mathrm{~km}$. An indepth description of the TMW can be found in Leblanc et al. (2012a). In addition, two other mobile lidar systems from the NASA-Goddard Space Flight Center (GSFC), referred to hereafter as "ALVICE" and "STROZ" lidars were employed during MOHAVE-2009 and used for MIPAS temperature, water vapor, and ozone validation.

The ALVICE system (Atmospheric Laboratory for Validation, Interagency Collaboration and Education) is a mobile facility that includes various atmospheric instruments in addition to the Raman lidar. The system provides, among other components, measurements of water vapor and rotational Raman temperature measurements, which were tested 
for the first time during the MOHAVE-2009 campaign. The performance of the various components of the ALVICE system are discussed in Whiteman et al. (2011). The vertical resolution of the ALVICE system ranges up to $1.2 \mathrm{~km}$ in the upper parts of the profile. For the comparison to MIPAS measurements, we used temperature and water vapor mixing ratio measurements from ALVICE. For water vapor, the socalled best estimate profiles were used. This best estimate product merges the variably smoothed, $1 \mathrm{~h}$ sum and all night lidar profiles and includes a ground value of mixing ratio derived from ground-based in-situ sensors. The all-night lidar product includes a correction for signal-dependent bias believed to be due to fluorescence of contaminants present in the lidar telescope.

The Stratospheric Ozone (STROZ) lidar, operational since 1989, was developed within GSFC Stratospheric Chemistry and Dynamics Branch to be an ozone, and temperature lidar validation standard within NDACC (formerly NDSC) (McGee et al., 1991, 1995). Other measurement capabilities have been added over the years (aerosols in 1992, and water vapor in 2005). Currently the lidar transmits a pair of wavelengths, $308 \mathrm{~nm}$ from a $\mathrm{XeCl}$ laser and $355 \mathrm{~nm}$ from a high powered Nd-YAG laser. The STROZ lidar operated in three separate modes during MOHAVE 2009. First, an ozone mode with a FOV of $2.3 \mathrm{mrad}$ and transmitting at $308 \mathrm{~nm}$ and $355 \mathrm{~nm}$ typically was used for two hours during which ozone, temperature, aerosol, and water vapor were retrieved. The second mode transmitted only $355 \mathrm{~nm}$ with the main telescope closed down to $1.0 \mathrm{mrad}$, a mode during which aerosol, temperature, and water vapor was retrieved. The third mode consisted of transmitting only $355 \mathrm{~nm}$ with a FOV of $1.0 \mathrm{mrad}$, but with a filter, which blocked $355 \mathrm{~nm}$ from the first telescope while transmitting 387 and $407 \mathrm{~nm}$ radiation. The block was placed ahead of the collimation optics of the main telescope. No such filter was placed in the 4 " receiver linked to the second telescope. This mode returned only water vapor data. The filter was used because it was shown from a previous MOHAVE campaign that fluorescence excited by the $355 \mathrm{~nm}$ within the receiver chain, although small, can (and did in the STROZ lidar case) produce a wet bias in the water vapor retrieval at high altitudes (low water vapor). The blocking filter greatly reduced but did not completely remove this interference from the STROZ data. The vertical resolution of the STROZ system ranges up to $1.5 \mathrm{~km}$ in the upper parts of the profile. A thorough description of the instrument and data will be presented in McGee et al. (2012).

Two other lidars permanently deployed at TMF and operated by JPL acquired tropospheric ozone, stratospheric ozone, and middle atmospheric temperature profiles throughout the MOHAVE-2009 campaign. The stratospheric ozone Differential Absorption Lidar (DIAL) is permanently deployed at TMF, and has acquired over 2000 routine profiles since 1989 ( $2 \mathrm{~h}$ per night, 3 to 4 nights per week). It uses two $\mathrm{XeCl}$ Excimer lasers and one Nd:YAG laser to transmit in the atmosphere at $308 \mathrm{~nm}$ (weakly absorbed by ozone) and $355 \mathrm{~nm}$ (non-absorbed). The backscattered light is collected on a $0.91 \mathrm{~m}$ diameter Newtonian telescope and sent to an optical receiver where it is separated in 6 channels, including two pairs of Rayleigh channels (low and high intensity), and one pair of Nitrogen Raman channels (for the ozone and temperature retrieval in the lower part of the stratosphere often affected by aerosols or thin clouds). Ozone is retrieved between the altitudes of $15 \mathrm{~km}$ and $50 \mathrm{~km}$ with a total uncertainty ranging from $5 \%$ (mid-stratosphere) to $15 \%$ (upper stratosphere), while temperature is retrieved between $15 \mathrm{~km}$ and $85 \mathrm{~km}$ with total uncertainty ranging from less than $1 \mathrm{~K}$ (lower stratosphere) to 5-10 K (75-85 km). A tropospheric ozone DIAL complements the stratospheric measurements since 1999. It uses a Nd:YAG laser with a fundamental at $1064 \mathrm{~nm}$ quadrupled to $266 \mathrm{~nm}$. The beam is splitted in two high-pressure cells filled with Hydrogen and Deuterium for a Raman-shift to $289 \mathrm{~nm}$ and $299 \mathrm{~nm}$ respectively. These transmitted UV wavelengths are in a more absorbing region than that used for the stratosphere in order to guarantee sufficient sensitivity in the ozone-poor troposphere. About 1500 tropospheric profiles (3-25 km with total uncertainty ranging from $3 \%$ to $15 \%$ ) have been acquired since 1999 .

\subsubsection{Radiosondes}

Two types of meteorological radiosondes, designed for worldwide use on operational basis, were launched during MOHAVE-2009, namely the iMET-1-RSB and Vaisala RS92 radiosondes. For validation of MIPAS, RS92 radiosonde data were used for temperature only, since the data on water vapor volume mixing ratio calculated from the relative humidities in the overlap region of MIPAS and RS92 measurements are not accurate enough for a meaningful validation. As shown by Hurst et al. (2011b) the iMet sonde temperature data are biased by $0.5 \mathrm{~K}$ versus the RS92 radiosondes, and the RS92RS92 comparisons suggest that the total uncertainty in RS92 temperature measurements is better than $0.5 \mathrm{~K}$ throughout the profile, which is consistent with an uncertainty analysis by Luers (1997) about an earlier version of this sensor. A total of 58 RS92 radiosondes were launched during MOHAVE2009. In 14 cases, two RS92 were mounted on the same balloon payload ("duals"). Data were received by two separate ground systems, one (called RS92_JPL in the following) owned, launched, and processed by the JPL lidar group, and the other one owned and operated by the ALVICE group (called RS92_GFSC in the following). For the two systems, the processing software (digicora) version is slightly different, and the GSFC sondes include a GPS receiver, while the JPL ones do not. Although it is not mandatory to distinguish between the JPL and GSFC RS92s since the accuracies are equivalent, we have kept them separate in the following. Further measurements from radiosondes come from frost point hygrometer launches. 


\subsubsection{Frost point hygrometers}

The balloon-borne NOAA frost point hygrometer (FPH) was first flown over Boulder, CO, in 1980 (Oltmans et al., 2000) and, to date, has produced a 31-yr record of stratospheric water vapor mixing ratios (Hurst et al., 2011a). Frost point hygrometers measure the frost point of air passing through the hygrometer, from which the partial pressure of water vapor is directly calculated. The technique relies on the maintenance of a stable frost (ice) layer on a temperature-controlled mirror. Under equilibrium conditions, the ice surface temperature and water vapor content of the passing air are related through the Clausius-Clapeyron equation. Water vapor partial pressure is divided by the dry atmospheric pressure to yield the water vapor volume mixing ratio.

Starting in 2003, the cryogenic frost point hygrometer $(\mathrm{CFH})$ was developed in parallel to the FPH, with an emphasis on reducing instrument size and weight and improving frost layer stability (Vömel et al., 2007). The CFH and NOAA FPH were developed independently, therefore there are subtle differences in the ways they operate. Neither instrument requires water vapor calibration standards or a water vapor calibration scale; only the mirror thermistor must be calibrated with high accuracy and this is accomplished using NIST-traceable standards.

Temperature and pressure measurements used to convert frost point hygrometer data into RH values and volume mixing ratios, respectively, are from the accompanying radiosondes on each balloon. Measurements of temperature and pressure from two different sondes are provided - one is an iMet1-RSB sonde (also called iMet sonde in this paper), the other a RS92 radiosonde. We have used the temperatures from the RS92 sondes for comparisons to MIPAS. Because there is an altitude-dependent pressure bias between the two types of radiosondes, the water vapor mixing ratios calculated using one set of pressure differs from the other. Above $20 \mathrm{~km}$ the pressure bias makes frost point hygrometer water vapor mixing ratios calculated using iMet sonde pressures 1-5\% higher than if calculated using RS92 sonde pressures (Hurst et al., 2011b). Below $20 \mathrm{~km}$, however, pressure differences between iMet and RS92 sondes are smaller, substantially decreasing the relative water vapor mixing ratio differences. We have used in our comparisons to MIPAS the water vapor mixing ratios calculated with RS92 sonde pressures.

The ozone data for balloon flights are from ozonesondes flown with the frost point hygrometers. All the ozonesondes were from the same manufacturer (EnSci) and were the same model (2Z). These ozonesondes are of the ECC (electrochemical concentration cell) type (Komhyr, 1969; Komhyr et al., 1995). There are no differences between the ozonesondes flown with NOAA FPH and CFH.

\subsubsection{Microwave radiometers}

Two ground-based microwave radiometers participated to the campaign, namely the Water Vapor Millimeter-wave Spectrometer (WVMS) permanently deployed by the US Naval Research Laboratory (NRL) at TMF (Nedoluha et al., 2011) and the portable MIddle Atmosphere WAter vapor RAdiometer (MIAWARA-C) from the University of Bern, Switzerland (Straub et al., 2010). During a 5-month validation campaign the standard deviation of the MLS (version 2) -WVMS differences was shown to be $5 \%$ from $26-70 \mathrm{~km}$ and the systematic difference was within $8 \%$ throughout this altitude range. Both instruments use the pressure broadening of the water vapor rotational transition absorption line near $22 \mathrm{GHz}$ for the retrieval of the altitude distribution of water vapor.

The daily profiles during the MOHAVE-2009 campaign cover an altitude range from about $30 \mathrm{~km}$ (26 km for WVMS, and $33 \mathrm{~km}$ for MIAWARA-C) to $70 \mathrm{~km}$ with a vertical resolution of 12 to $15 \mathrm{~km}$. The altitudes covered depend on the signal-to-noise ratios of the integrated spectra, which themselves depend on the tropospheric conditions. Analysis of the MIAWARA-C forward and retrieval model provides an estimate of errors in the profiles which are typical for ground based $22-\mathrm{GHz}$ water vapor radiometers. The total systematic 2- $\sigma$ error, taking uncertainties from the a priori temperature information, the calibration and the spectroscopy into account, is below $16 \%$ at all altitudes, while the random error from measurement noise increases from $10 \%$ at altitudes up to $50 \mathrm{~km}$ to $25 \%$ between 50 and $70 \mathrm{~km}$.

\subsubsection{FTIR ground-based spectrometer MkIV}

The MkIV FTIR spectrometer was designed and built at JPL in 1984 (Toon, 1991). Since then it has been operated on different platforms (ground-based, balloon-borne, and airborne) in the framework of a large variety of different campaigns dedicated mainly to the investigation of stratospheric chemistry. The MkIV can measure high-resolution spectra (maximum optical path difference of up to $200 \mathrm{~cm}$ ) and covers a very broad spectral range $\left(650-5650 \mathrm{~cm}^{-1}\right)$. For the MOHAVE-2009 campaign water vapor profiles were retrieved following the method described in Schneider et al. (2010). The range of sensitivity for the MkIV instrument is limited from the ground to the upper troposphere which makes comparisons to MIPAS difficult due to a very small overlap range.

\subsection{Co-located satellite observations}

\subsubsection{Aura/MLS}

Aura MLS was launched on 15 July 2004 into a near polar sun-synchronous orbit at $705 \mathrm{~km}$ altitude, with ascending equatorial crossing time of 13:45 LT (Schoeberl et al., 2006). It scans the Earth limb providing 240 scans per orbit, 
spaced $165 \mathrm{~km}$ along the orbit track, and $\sim 3500$ vertical profiles per day, with near pole-to-pole global latitudinal coverage from $82^{\circ} \mathrm{S}$ to $82^{\circ} \mathrm{N}$. MLS observes thermal microwave - far infrared emission from the Earth's atmosphere in five spectral regions. Temperature is retrieved from the $118 \mathrm{GHz}$ $\mathrm{O}_{2}$ and $234 \mathrm{GHz} \mathrm{O}^{18} \mathrm{O}$ lines as described in Schwartz et al. (2008), while $\mathrm{H}_{2} \mathrm{O}$ is retrieved from measurements of the $183 \mathrm{GHz} \mathrm{H} \mathrm{H}_{2} \mathrm{O}$ rotational line spectrum (Read et al., 2007; Lambert et al., 2007), and ozone is retrieved from the 236 and $243 \mathrm{Ghz}$ lines (Froidevaux et al., 2008). The MLS data processing algorithm is based on the optimal estimation method and uses a two-dimensional retrieval-approach to determine temperature, geopotential height and trace gas concentrations (Livesey et al., 2008). Most data products are retrieved on a fixed vertical pressure grid with 6 levels per decade change in pressure from the troposphere to the stratosphere. In the case of temperature and $\mathrm{H}_{2} \mathrm{O}$ (and ozone for data version 3.3), the vertical pressure grid is finer in the troposphere and the lower stratosphere, with 12 levels per decade change in pressure between 1000 and $22 \mathrm{hPa}(0-25 \mathrm{~km})$. For this study MLS version 3.3 (v3.3) data have been used, and geopotential heights (GPH) provided within the data files have been used as altitude registration. This produces an altitude shift of 0 to $500 \mathrm{~m}$ over the altitude range of 0 to $55 \mathrm{~km}$, which has been considered acceptable but should be kept in mind when analysing the comparisons. Read et al. (2007) and Lambert et al. (2007) have reported on vertical oscillations in v2.2 $\mathrm{H}_{2} \mathrm{O}$ by up to $8 \%$ at $31.6 \mathrm{hPa}$ which, however, have been eliminated in MLS version 3.3.

MIPAS data recorded in the special Upper Troposphere/Lower Stratosphere (UTLS-1) mode have already been compared to MLS v2.2 data by Chauhan et al. (2009). Temperature, water vapor and ozone were compared along latitudes, and on basis of global means. For temperature, vertical oscillations typically up to $\pm 4 \mathrm{~K}$ were observed between MIPAS and MLS in the pressure/latitude range from 316.2 to $100.0 \mathrm{hPa}$ and $90^{\circ} \mathrm{S}$ to $90^{\circ} \mathrm{N}$, respectively. MIPAS was colder by up to $1 \mathrm{~K}$ than MLS at the $21.5 \mathrm{hPa}$ pressure level. In the middle and upper stratosphere MIPAS and MLS were biased within $\pm 3 \mathrm{~K}$. Differences up to $\pm 4 \mathrm{~K}$ in the UTLS and in the stratosphere were in agreement with the differences observed for MLS in comparison to other satellite instruments (Schwartz et al., 2008). The global mean altitude-dependent bias between MIPAS and MLS temperatures varied between $\pm 2.5 \mathrm{~K}$ peak-to-peak and was within the combined systematic errors over the complete pressure range $316-0.1 \mathrm{hPa}$ with small exceptions at 14.6 and $3.2 \mathrm{hPa}$.

Regarding water vapor, MIPAS was wetter than MLS between 316.2 and $177.8 \mathrm{hPa}$ over the mid-latitudes and poles by about $50 \%$ (up to $100 \%$ ), more prominently over the Southern Hemisphere. From 215.4 to $177.8 \mathrm{hPa}$ over the sub-tropics and tropics, MIPAS $\mathrm{H}_{2} \mathrm{O}$ volume mixing ratios (VMRs) were drier by $10 \%$ compared to MLS. In the lower stratosphere (146.7-56.2 hPa), the MIPAS/MLS water vapor comparison showed oscillations of $\pm 1 \mathrm{ppmv}( \pm 10 \%)$ over all latitudes. Oscillations up to $10 \%$ were also observed between $31.6-26.1 \mathrm{hPa}$ for all latitudes. In the middle and upper stratosphere between $26.1-0.2 \mathrm{hPa}$ the agreement between MIPAS and MLS was within $\pm 5 \%$. The oscillations observed in the height range 31.6 to $26.1 \mathrm{hPa}$ were due to a known artefact in MLS $\mathrm{H}_{2} \mathrm{O}$ v2.2 retrievals (Lambert et al., 2007) which has been removed for version 3.3. The altitude-dependent global mean water vapor bias was within \pm 0.2 ppmv ( $\pm 4 \%$ ) between 100 to $0.1 \mathrm{hPa}$, with an exception at $31.6 \mathrm{hPa}$ and $26.1 \mathrm{hPa}$ due to the problem in the MLS v2.2 data as mentioned above. From $316 \mathrm{hPa}$ to $100 \mathrm{hPa}$ the mean bias in water vapor varied from $+12 \%$ to $-4 \%$.

MIPAS ozone was up to $10 \%$ higher than MLS in the upper stratosphere $(6.8-1.4 \mathrm{hPa})$ over the southern midlatitudes and subtropics. Over the tropics at $31.6 \mathrm{hPa}$ a difference (MIPAS minus MLS) of 0.5 ppmv or $20 \%$ was observed. Over the tropics and sub-tropics above the tropical tropopause layer (TTL) (100.0-68.1 hPa) relative differences as high as $+90 \%$ to $-80 \%$ were observed, while over the South pole in the height range 146.7 to $100.0 \mathrm{hPa}$ differences were up to $10 \%$. The high relative differences in the tropics and sub-tropics in the TTL were partly explained by low ozone concentrations and strong vertical gradients in this region. The global altitude-dependent mean ozone bias was found to be $5 \%$ or less than $0.35 \mathrm{ppmv}$, with MIPAS being always higher than MLS, and peaking at about $5 \mathrm{hPa}$.

\subsubsection{ACE-FTS}

The Atmospheric Chemistry Experiment Fourier Transform Spectrometer (ACE-FTS) is the principal instrument onboard the Canadian SCISAT satellite (Bernath et al., 2005). SCISAT was launched on 12 August 2003 into a $74^{\circ}$ inclined orbit with an altitude of $650 \mathrm{~km}$. ACE-FTS is a highresolution FTS with the following specifications: spectra are recorded from $750 \mathrm{~cm}^{-1}$ to $4400 \mathrm{~cm}^{-1}$ (13.3 to $2.2 \mu \mathrm{m}$ ), at a resolution of $0.02 \mathrm{~cm}^{-1}( \pm 25 \mathrm{~cm}$ maximum optical path difference). The instrument measures using solar occultation and provides up to 30 measurements per day. It records one full spectrum in about $2 \mathrm{~s}$ with a signal-to-noise ratio between 300:1 and 400:1 near the center of the wavenumber range. The delay between consecutive spectra gives a vertical spacing varying from 1.5 to $6 \mathrm{~km}$ depending on the angle between the orbit plane and the viewing direction with a maximum altitude resolution of approximately $3 \mathrm{~km}$ due to the field-of-view of the instrument $(1.25 \mathrm{mrad})$. Details of ACE-FTS spectral inversion process are described in Boone et al. (2005). In a two-step process, temperature and pressure are retrieved from $\mathrm{CO}_{2}$ transitions first and then these parameters are used retrieve the trace gas profiles. We have used the version 3 retrievals for validation of MIPAS data. This newest data version has reduced the occurrence of oscillations in the temperature profiles and the microwindows for all trace gases have been updated. This dataset is in the process of being validated. 


\subsubsection{AIRS}

The Atmospheric InfraRed Sounder (AIRS) was launched into Earth orbit on 4 May 2002 on board the Aqua satellite, part of the NASA Earth Observing System (Chahine et al., 2006). AIRS is a medium-resolution infrared grating spectroradiometer. As a multi-aperture slit and pupilimaging system, a diffraction grating disperses the incoming infrared radiation into 17 linear detector arrays comprising 2378 spectral samples. At long wavelengths, the spectral resolution is about $0.5 \mathrm{~cm}^{-1}$ decreasing to about $2 \mathrm{~cm}^{-1}$ at shorter wavelengths. The AIRS retrieval is based on iterative least squares physical inversion of clear column radiances following the approach of Chahine $(1968,1977)$. The retrieval of the AIRS water vapor profile uses a large set of channels associated with the strong $6-\mu \mathrm{m}$ water band, while temperature information is derived from the 15 and $4.3-\mu \mathrm{m}$ $\mathrm{CO}_{2}$ bands, and ozone is retrieved from the 9.6- $\mu \mathrm{m}$ ozone band (Susskind et al., 2003, 2006). Water vapor amount is retrieved at twelve standard pressure levels between the surface and $100 \mathrm{hPa}$, though sensitivity is low for mixing ratios of about 10 ppmv or less (Gettelman et al., 2004; Fetzer et al., 2008). AIRS water vapor retrievals have been validated versus aircraft and balloon in situ measurements (Hagan et al., 2004; Gettelman et al., 2004; Tobin et al., 2006) and versus MLS (Fetzer et al., 2008).

\section{Validation method}

The coincidence radius and time applied in this study were $1000 \mathrm{~km}$ and $4 \mathrm{~h}$. If several coincident profiles to the same MIPAS profile or correlative measurement profile were found, we have used all coincident measurements, even if this introduces some interdependence in the data set. This was done in order not to reduce the size of the statistical ensemble. An overview of the numbers of coincidences is given in Table 3. Tests have shown that the conclusions from the comparison of all coincident measurements do not differ significantly from those where only unique MIPAS - reference pairs were used.

Since most of the correlative measurements have a much different vertical sampling and resolution than the MIPAS measurements, we have resampled the profiles $x=$ $\left(x_{1}, \ldots, x_{n}\right)^{T}$ on a common altitude grid and degraded the better-resolved profile to the vertical resolution of the lowerresolved profile by application of the averaging kernel and a priori profile of the latter. Typically, profiles of lower vertical resolution are represented on a coarser altitude grid and vice versa. As a first step, both profiles are sampled on a common altitude grid. Resampling of a coarse profile $\boldsymbol{x}_{\mathrm{c}}$ on a fine grid can be written as

$\boldsymbol{x}_{\mathrm{cf}}=\mathbf{W} \boldsymbol{x}_{\mathrm{c}}$,

where $\mathbf{W}$ is an interpolation matrix. The inverse operation, to map a high-resolved profile $\boldsymbol{x}_{\mathrm{f}}$ on a less dense grid, is not
Table 3. Number of observations coincident with MIPAS for temperature, water vapor, and ozone.

\begin{tabular}{lrrr}
\hline Instrument & Temperature & Water vapor & Ozone \\
\hline TMW/TMF lidar & 22 & 22 & 27 \\
STROZ lidar & 31 & 18 & 27 \\
ALVICE lidar & 68 & 74 & - \\
CFH $^{1}$ & 18 & 18 & 18 \\
NOAA FPH & 11 & 11 & 11 \\
RS92_GSFC & 44 & - & - \\
RS92_JPL & 81 & - & - \\
WVMS & - & 61 & - \\
MIAWARA-C & - & 116 & - \\
MkIV & - & 454 & - \\
Aura/MLS v3.3 & 47 & 43 & 47 \\
ACE-FTS v3 & 5 & 5 & 5 \\
AIRS & 2696 & 1054 & - \\
\hline
\end{tabular}

$1 \mathrm{~T}$ from radiosondes (RS92) and $\mathrm{O}_{3}$ from ozonesondes flown with the frost point hygrometers.

unique but a reasonable recipe to achieve this is (Rodgers, 2000, Chapter 10.3.1)

$\boldsymbol{x}_{\mathrm{fc}}=\mathbf{V} \boldsymbol{x}_{\mathrm{f}}$,

where

$\mathbf{V}=\left(\mathbf{W}^{T} \mathbf{W}\right)^{-1} \mathbf{W}^{T}$,

which satisfies $\mathbf{V W}=\mathbf{I}, \mathbf{I}=$ unity. The application of the averaging kernel $\mathbf{A}_{\mathrm{c}}$ of the low-resolved profile $\boldsymbol{x}_{\mathrm{c}}$ to the betterresolved profile $\boldsymbol{x}_{\mathrm{f}}$ under consideration of the a priori profile $\boldsymbol{x}_{\mathrm{a}}$ of the low-resolved retrieval can either be performed on the coarse altitude grid

$\tilde{\boldsymbol{x}}_{\mathrm{fc}}=\mathbf{A}_{\mathrm{c}} \mathbf{V} \boldsymbol{x}_{\mathrm{f}}+\left(\mathbf{I}-\mathbf{A}_{\mathrm{c}}\right) \boldsymbol{x}_{\mathrm{a}}$

or on the fine altitude grid

$\tilde{\boldsymbol{x}}_{\mathrm{f}}=\mathbf{W} \mathbf{A}_{\mathrm{c}} \mathbf{V} \boldsymbol{x}_{\mathrm{f}}+\mathbf{W}\left(\mathbf{I}-\mathbf{A}_{\mathrm{c}}\right) \boldsymbol{x}_{\mathrm{a}}$.

We have chosen the intercomparison on the coarse grid, according to Eq. (4). For most intercomparisons in this paper, particular those of MIPAS versus in situ measurements or lidar profiles, the correlative measurements were resampled on the MIPAS vertical grid and degraded to the MIPAS resolution. Exceptions are profiles from MIAWARA-C, WVMS, MkIV, and AIRS whose vertical resolution is worse than that of MIPAS. In these cases, the profiles were interpolated to a grid which was the combination of both original grids, containing all grid points from the one and the other original grid, and the MIPAS profiles were degraded with the averaging kernel of the correlative measurement where available instead.

These transformations also have to be applied to the related covariance matrices $\mathbf{S}$. The transformation of the error 
covariance matrix $\mathbf{S}_{\mathrm{f}}$ of the better resolved measurement on the finer grid onto the coarser grid is

$\tilde{\mathbf{S}}_{\mathrm{fc}}=\mathbf{A}_{\mathrm{c}} \mathbf{V} \mathbf{S}_{\mathrm{f}} \mathbf{V}^{T} \mathbf{A}_{\mathrm{c}}^{T}$.

For hybrid cases, e.g. when the coarser resolved profiles are represented on a finer grid than that on which the better resolved data are represented, or if one grid is finer in one altitude region but coarser in another, the tools discussed above can easily be combined to suit the particular application.

In case of MIPAS water vapor data there is another complication which is that instead of mixing ratios the logarithms of water vapor mixing ratios are retrieved; also the averaging kernels and covariance matrices refer to the logarithms of the water vapor mixing ratios.

The application of MIPAS averaging kernels to a better resolved profile on the basis of the coarse-grid averaging kernel $\mathbf{A}_{\text {Inc }}$ of the logarithm of the water vapor mixing ratio then is

$\tilde{\boldsymbol{x}}_{\mathrm{fc}}=\exp \left(\mathbf{A}_{\operatorname{lnc}} \mathbf{V} \ln \left(\boldsymbol{x}_{\mathrm{f}}\right)+\left(\mathbf{I}-\mathbf{A}_{\operatorname{lnc}}\right) \ln \left(\boldsymbol{x}_{\mathrm{a}}\right)\right)$.

Also the covariance matrix of the fine-grid correlative measurement has to be transformed into the log-space before the logarithmic averaging kernels of MIPAS can be applied. Equation (6) becomes

$\tilde{\mathbf{S}}_{\text {lnfc }}=\mathbf{A}_{\operatorname{lnc}} \mathbf{V S} \mathbf{S}_{\operatorname{lnf}} \mathbf{V}^{T} \mathbf{A}_{\text {lnc }}^{T}$,

where $\mathbf{S}_{\operatorname{lnf}}$ is calculated from the original covariance matrix in the linear domain, $\mathbf{S}_{\mathrm{f}}$, by generalized Gaussian error propagation as

$\mathbf{S}_{\operatorname{lnf}}=\left(\begin{array}{ccc}\frac{1}{x_{1 ; \mathrm{f}}}, & \ldots, & 0 \\ \vdots & \ddots & \vdots \\ 0, & \ldots & \frac{1}{x_{n ; \mathrm{f}}}\end{array}\right) \mathbf{S}_{\mathrm{f}}\left(\begin{array}{ccc}\frac{1}{x_{1 ; \mathrm{f}}}, & \ldots, & 0 \\ \vdots & \ddots & \vdots \\ 0, & \ldots & \frac{1}{x_{n ; \mathrm{f}}}\end{array}\right)$.

The back-transformation of the error covariance matrix into the linear domain after application of the logarithmic averaging kernel is calculated as

$\tilde{\mathbf{S}}_{\mathrm{fc}}=\left(\begin{array}{ccc}\tilde{x}_{1 ; \mathrm{fc}}, \ldots, & 0 \\ \vdots & \ddots & \vdots \\ 0, & \ldots & \tilde{x}_{n ; \mathrm{fc}}\end{array}\right) \tilde{\mathbf{S}}_{\mathrm{lnfc}}\left(\begin{array}{ccc}\tilde{x}_{1 ; \mathrm{fc}}, & \ldots & 0 \\ \vdots & \ddots & \vdots \\ 0, & \ldots & \tilde{x}_{n ; \mathrm{fc}}\end{array}\right)$.

In the case when MIPAS water vapor is compared to profiles from a measurement of lower resolution and coarser grid, Eq. (4) can be directly applied to MIPAS profiles in the volume mixing ratio (VMR) domain without any further complication. The transformation of the MIPAS logarithmic covariance matrix into the linear domain again applies the formalism of Eq. (10). This applies to the WVMS and the MIAWARA-C experiment.

For AIRS, no averaging kernels are provided, and the data are provided on a vertical grid which is almost identical to the MIPAS grid. In this case, the data are compared as they are, without any transformation. Different altitude resolutions have to be kept in mind when the differences are explained.
Mark IV water vapor retrievals are performed in the logarithm domain, too. Their averaging kernels can be directly used to transform the logarithmic MIPAS covariance matrix:

$\tilde{\mathbf{S}}_{\mathrm{lnfc}}=\mathbf{A}_{\operatorname{lnc}} \mathbf{V S} \mathbf{S}_{\operatorname{lnf}} \mathbf{V}^{T} \mathbf{A}_{\text {lnc }}^{T}$

Table 4 presents a summary on the transformations applied to each MIPAS-validation data set pair. After these transformations of measurements and their error estimates to a common grid and after having degraded the better resolved profiles to the lower resolution of the other measurement, the comparison of data is performed. For evaluation of individual pairs of correlative measurements $x_{i ; \mathrm{c}}$ and $\tilde{x}_{i \text {;fc }}$, we compare their differences to their combined accuracies (whenever available; for some instruments only random error or measurement noise estimates are available which then are used instead) which are calculated as

$\sigma_{i ; \mathrm{diff}}=\sqrt{\sigma_{i ; \mathrm{c}}^{2}+\tilde{\sigma}_{i ; \mathrm{fc}}^{2}}$

with $\sigma_{i ; \mathrm{c}}^{2}$ being the variance of the coarser measurement and $\tilde{\sigma}_{i ; \mathrm{fc}}^{2}$ being that of the degraded finer measurement on the coarser grid, both at altitude $i$. MIPAS error estimates include measurement noise error, further random parameter errors and systematic errors. We have used the errors provided in the data files of the correlative instruments as total uncertainty without separating into various error sources.

According to von Clarmann (2006), we first assess the bias between MIPAS and the correlative measurements, before the precision validation is performed. The bias $b_{i}$ is the mean difference between the MIPAS profiles and the coincident observations after convolution of the better resolved profile with the averaging kernel of the lower resolved measurement:

$b_{i}=\frac{\sum_{n=1}^{N_{i}}\left(x_{n, i ; \mathrm{c}}-\tilde{x}_{n, i ; \mathrm{fc}}\right)}{N_{i}}$.

Here the bias $b_{i}$ is calculated independently for each altitude grid point $i$ from the available $N_{i}$ coincident observations. $N_{i}$ can be different for different altitudes because the altitude coverage of a measurement system under assessment may vary from profile measurement to profile measurement. The standard error of the bias, which is also the biascorrected root mean squares (rms) difference of the profiles, is calculated as:

$\sigma_{i ; \text { bias }}=\sqrt{\frac{\sum_{n=1}^{N_{i}}\left(x_{n, i ; \mathrm{c}}-\tilde{x}_{n, i ; \mathrm{fc}}-b_{i}\right)^{2}}{N_{i}\left(N_{i}-1\right)}}$.

We consider the bias $b_{i}$ as clearly insignificant if the interval $b_{i} \pm \sigma_{i}$; bias includes zero. Additionally, we compare the bias to the systematic error of MIPAS (correctly it should be compared to the combined systematic error, i.e. square root of the sum of squared systematic errors, however, we take the error estimates of the correlative instruments as total (random) uncertainty and have not used any information on 
Table 4. Transformations applied to each MIPAS-validation data set pair.

\begin{tabular}{|c|c|c|}
\hline Instrument & $\begin{array}{l}\text { Measured } \\
\text { quantity }\end{array}$ & $\begin{array}{l}\text { Transformation } \\
\text { applied }\end{array}$ \\
\hline \multirow[t]{3}{*}{ TMW/TMF lidar } & $T$ & Eqs. (4), (6) on MIPAS grid, MIPAS $\mathbf{A}_{\mathrm{c}}$ applied \\
\hline & $\mathrm{H}_{2} \mathrm{O}$ & Eqs. (7), (8)-(10) on MIPAS grid, MIPAS $\mathbf{A}_{\text {lnc }}$ applied \\
\hline & $\mathrm{O}_{3}$ & Eqs. (4), (6) on MIPAS grid, MIPAS $\mathbf{A}_{c}$ applied \\
\hline \multirow[t]{3}{*}{ STROZ lidar } & $T$ & Eqs. (4), (6) on MIPAS grid, MIPAS $\mathbf{A}_{\mathrm{c}}$ applied \\
\hline & $\mathrm{H}_{2} \mathrm{O}$ & Eqs. (7), (8)-(10) on MIPAS grid, MIPAS $\mathbf{A}_{\operatorname{lnc}}$ applied \\
\hline & $\mathrm{O}_{3}$ & Eqs. (4), (6) on MIPAS grid, MIPAS $\mathbf{A}_{c}$ applied \\
\hline \multirow[t]{2}{*}{ ALVICE lidar } & $T$ & Eqs. (4), (6) on MIPAS grid, MIPAS $\mathbf{A}_{\mathrm{c}}$ applied \\
\hline & $\mathrm{H}_{2} \mathrm{O}$ & Eqs. (7), (8)-(10) on MIPAS grid, MIPAS $\mathbf{A}_{\operatorname{lnc}}$ applied \\
\hline \multirow[t]{3}{*}{$\mathrm{CFH}^{1}$} & $T$ & Eqs. (4), (6) on MIPAS grid, MIPAS $\mathbf{A}_{c}$ applied \\
\hline & $\mathrm{H}_{2} \mathrm{O}$ & Eqs. (7), (8)-(10) on MIPAS grid, MIPAS $\mathbf{A}_{\operatorname{lnc}}$ applied \\
\hline & $\mathrm{O}_{3}$ & Eqs. (4), (6) on MIPAS grid, MIPAS $\mathbf{A}_{c}$ applied \\
\hline \multirow[t]{3}{*}{ NOAA FPH $^{1}$} & $T$ & Eqs. (4), (6) on MIPAS grid, MIPAS $\mathbf{A}_{c}$ applied \\
\hline & $\mathrm{H}_{2} \mathrm{O}$ & Eqs. (7), (8)-(10) on MIPAS grid, MIPAS $\mathbf{A}_{\text {lnc }}$ applied \\
\hline & $\mathrm{O}_{3}$ & Eqs. (4), (6) on MIPAS grid, MIPAS $\mathbf{A}_{c}$ applied \\
\hline RS92_GSFC & $T$ & Eqs. (4), (6) on MIPAS grid, MIPAS $\mathbf{A}_{\mathrm{c}}$ applied \\
\hline RS92_JPL & $T$ & Eqs. (4), (6) on MIPAS grid, MIPAS $\mathbf{A}_{\mathrm{c}}$ applied \\
\hline WVMS & $\mathrm{H}_{2} \mathrm{O}$ & Eqs. (4), (8)-(10) on union grid, WVMS $\mathbf{A}_{\mathrm{c}}$ applied to MIPAS \\
\hline MIAWARA-C & $\mathrm{H}_{2} \mathrm{O}$ & Eqs. (4), (8)-(10) on union grid, MIAWARA-C $\mathbf{A}_{\mathrm{c}}$ applied to MIPAS \\
\hline MkIV & $\mathrm{H}_{2} \mathrm{O}$ & Eqs. (4), (11) on union grid, MkIV $\mathbf{A}_{c}$ applied to MIPAS $\ln \left[\mathrm{H}_{2} \mathrm{O}\right]$ \\
\hline \multirow[t]{3}{*}{ Aura/MLS } & $T$ & Eqs. (4), (6) on MIPAS grid, MIPAS $\mathbf{A}_{c}$ applied \\
\hline & $\mathrm{H}_{2} \mathrm{O}$ & Eqs. (7), (8)-(10) on MIPAS grid, MIPAS $\mathbf{A}_{\operatorname{lnc}}$ applied \\
\hline & $\mathrm{O}_{3}$ & Eqs. (4), (6) on MIPAS grid, MIPAS $\mathbf{A}_{c}$ applied \\
\hline \multirow[t]{3}{*}{ ACE-FTS } & $T$ & Eqs. (4), (6) on MIPAS grid, MIPAS $\mathbf{A}_{c}$ applied \\
\hline & $\mathrm{H}_{2} \mathrm{O}$ & Eqs. (7), (8)-(10) on MIPAS grid, MIPAS $\mathbf{A}_{\operatorname{lnc}}$ applied \\
\hline & $\mathrm{O}_{3}$ & Eqs. (4), (6) on MIPAS grid, MIPAS $\mathbf{A}_{c}$ applied \\
\hline \multirow[t]{2}{*}{ AIRS } & $T$ & Interpolation to union grid, no averaging kernel applied \\
\hline & $\mathrm{H}_{2} \mathrm{O}$ & Interpolation to union grid, no averaging kernel applied \\
\hline
\end{tabular}

${ }^{1} T$ from radiosondes (RS92) and $\mathrm{O}_{3}$ from ozonesondes flown with the frost point hygrometers.

the systematic error alone), in order to assess if the bias can be explained by known systematic uncertainties.

The bias-corrected rms difference between coincident measurements $\sigma_{i}$;iff is linked to the standard error of the bias by

$\sigma_{i ; \text { diff }}=\sqrt{N_{i}} \sigma_{i} ;$ bias

In the case of perfect co-incidences and valid random error estimates of both measurements, $\sigma_{i}$;iff is expected to equal the combined single profile random error (see Eq. 12, but without consideration of systematic error terms) and thus is used for precision validation.

For the standard approach, we have not separated the available measurements into day and night profiles, although in the upper stratosphere and mesosphere, some effects of nonlocal thermodynamic equilibrium (non-LTE) triggered by illumination are known to be present in MIPAS profiles. These aspects are discussed in Sects. 5.1.5, 5.2.6, and 5.3.4, related to the assessment of systematic biases due to non-LTE effects. Some instruments provide measurements from various integration intervals, for example $6 \mathrm{~h}$ versus $24 \mathrm{~h}$ measure- ments of the microwave instruments, or nightly means versus 10-min measurements of TMF lidar. We have selected the nightly mean measurements from the lidars, the 24-h measurements from WVMS, and the 6-h measurements from MIAWARA-C for comparison, using the assigned measurement time in the file headers for determination of a potential coincidence.

In all figures in the following, the differences provided are MIPAS profiles minus the correlative measurements, the one adjusted in vertical resolution by the averaging kernel of the other where appropriate, and brought to the same (coarser) vertical grid. For individual profiles, the blue curve represents the MIPAS profile with the blue error bars representing the MIPAS error due to measurement noise, the green line and green error bars represent the original correlative measurement with its provided error, and the black line gives the correlative measurement transformed with the MIPAS averaging kernel. In case of comparison to WVMS, MIAWARA$\mathrm{C}$ and MkIV, the black line is the MIPAS profile transformed with the averaging kernel of those measurements. In case of AIRS, no degradation with the averaging kernels of AIRS 
has been performed. In the right panel of all these figures, the difference of individual profiles is compared to the combined total errors of the two instruments according to Eq. (12).

For averages over the coincident measurements, the blue and black line give the average of the MIPAS profiles and the averaging-kernel transformed correlative measurements, respectively, except for WVMS, MIAWARA-C, MkIV, and AIRS, in which cases MIPAS has been transformed. The bias is provided together with its standard error (shown as error bars) and the MIPAS systematic errors (dashed lines) in a second panel. In the third panel, the combined total precision of individual measurement pairs according to Eq. (12), but without consideration of the MIPAS systematic error (dashed lines), is compared to the bias-corrected rms differences (dotted lines). Again, in case of the correlative measurements we have not distinguished between various error sources, and the error as provided is used. For water vapor, profiles are presented on a logarithmic axis, and relative differences are shown: these are the mean differences of the profiles given as percentage of the mean profile of the correlative measurement.

\section{Validation results}

\subsection{Temperature}

\subsubsection{Comparison to lidar temperatures}

Temperature measurements by lidars during the MOHAVE2009 campaign are available from the instruments TMF lidar, STROZ and ALVICE. While TMF lidar covers all altitudes from the ground to the mesopause, STROZ measurements are available up to the lower mesosphere, and ALVICE measurements cover the troposphere and the lowermost stratosphere.

Figure 1 shows the comparison of a MIPAS temperature profile measured on 18 October 2009 with the TMF lidar coincidence of a nightly mean profile. The MIPAS - TMF lidar difference is mostly within or only slightly larger than the total error of MIPAS. Below the tropopause, MIPAS temperatures are higher than TMF lidar temperatures by about 1.5 to $2 \mathrm{~K}$, while just above the tropopause, they are lower by about the same amount, reproducing very well the well-known signatures found in differences relative to ECMWF data. Above the tropopause up to about $50 \mathrm{~km}$, MIPAS is within $2 \mathrm{~K}$ of the TMF lidar temperature profile, while in the mesosphere, the differences are better than $3 \mathrm{~K}$. The bias derived from all available 22 coincidences (see Fig. 2, top row) is less than $1 \mathrm{~K}$, except below $10 \mathrm{~km}$, directly above the tropopause, near $42 \mathrm{~km}$, and near $60 \mathrm{~km}$. In the stratosphere, the bias is always negative, while in the troposphere, it is positive. The systematic errors of MIPAS cannot explain the bias (see Fig. 2, top row, middle panel). Further, the bias-corrected rms differences are far above the combined precision of both

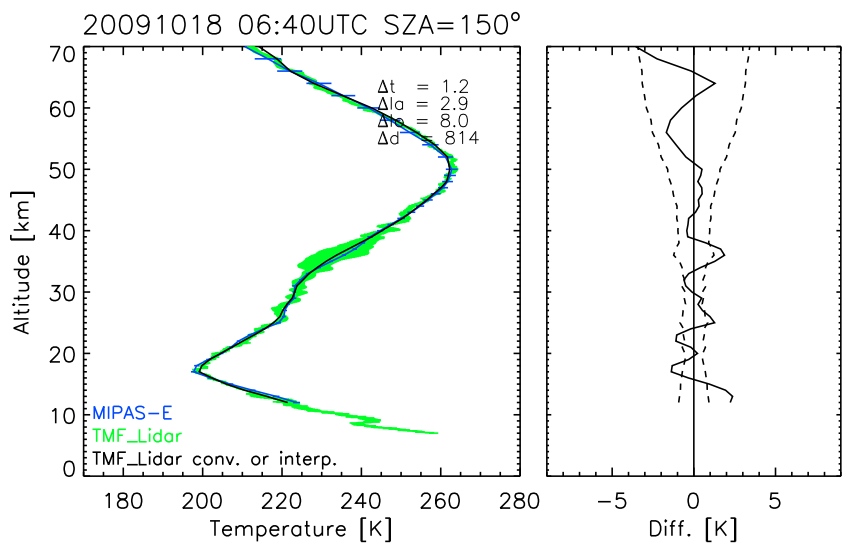

Fig. 1. Left: single MIPAS temperature profile (blue) measured on 18 October 2009 and a coincident profile (within $1000 \mathrm{~km}, 4 \mathrm{~h}$ ) of nightly mean TMF lidar measurements (green). The solid black line gives the TMF lidar profile degraded with the MIPAS averaging kernel. The blue and green error bars are measurement noise errors of the MIPAS and the correlative measurement, respectively. $\Delta t$ is the time difference in hours, $\Delta d$ the spatial difference in kilometers, and $\Delta$ la and $\Delta$ lo are the latitude and longitude differences, respectively, in degrees. Right: the black solid line provides the absolute difference between the coincident profiles, while the dashed line is the combined total error (including measurement noise, further random errors and systematic error components) of the two instruments, both on the coarser grid. For more details, see text.

instruments (see Fig. 2, top row, right panel), which hints towards an underestimation of the random error of one or both instruments. Comparing the same set of TMF lidar observations to ECMWF temperature profiles interpolated to the geolocations of the related MIPAS measurements (not shown) demonstrates that ECMWF is virtually bias-free to the TMF lidar measurements; this comparison hints towards a bias of -0.5 to $-1 \mathrm{~K}$ of MIPAS temperatures throughout the stratosphere.

Comparison of MIPAS temperature profiles to STROZ lidar measurements (see Fig. 2, middle row) indicates that no significant bias in MIPAS temperature data is present between 18 and $50 \mathrm{~km}$. MIPAS temperatures are higher by up to $2 \mathrm{~K}$ just below the tropopause, but lower than STROZ further down in the troposphere. Above the stratopause, the comparison indicates a strong low bias of MIPAS. The bias in the troposphere and mesosphere is much larger than the MIPAS systematic errors; this means that the differences cannot be explained by known systematic uncertainties of MIPAS. The bias-corrected root mean squares differences are about twice as large as the combined precisions of the instruments.

A comparison to ALVICE profiles is possible in the troposphere and lowermost stratosphere only. The already observed pattern of higher temperatures from MIPAS (1$2 \mathrm{~K}$ ) below the tropopause and lower temperatures above the tropopause is also reproduced by the comparison to ALVICE 

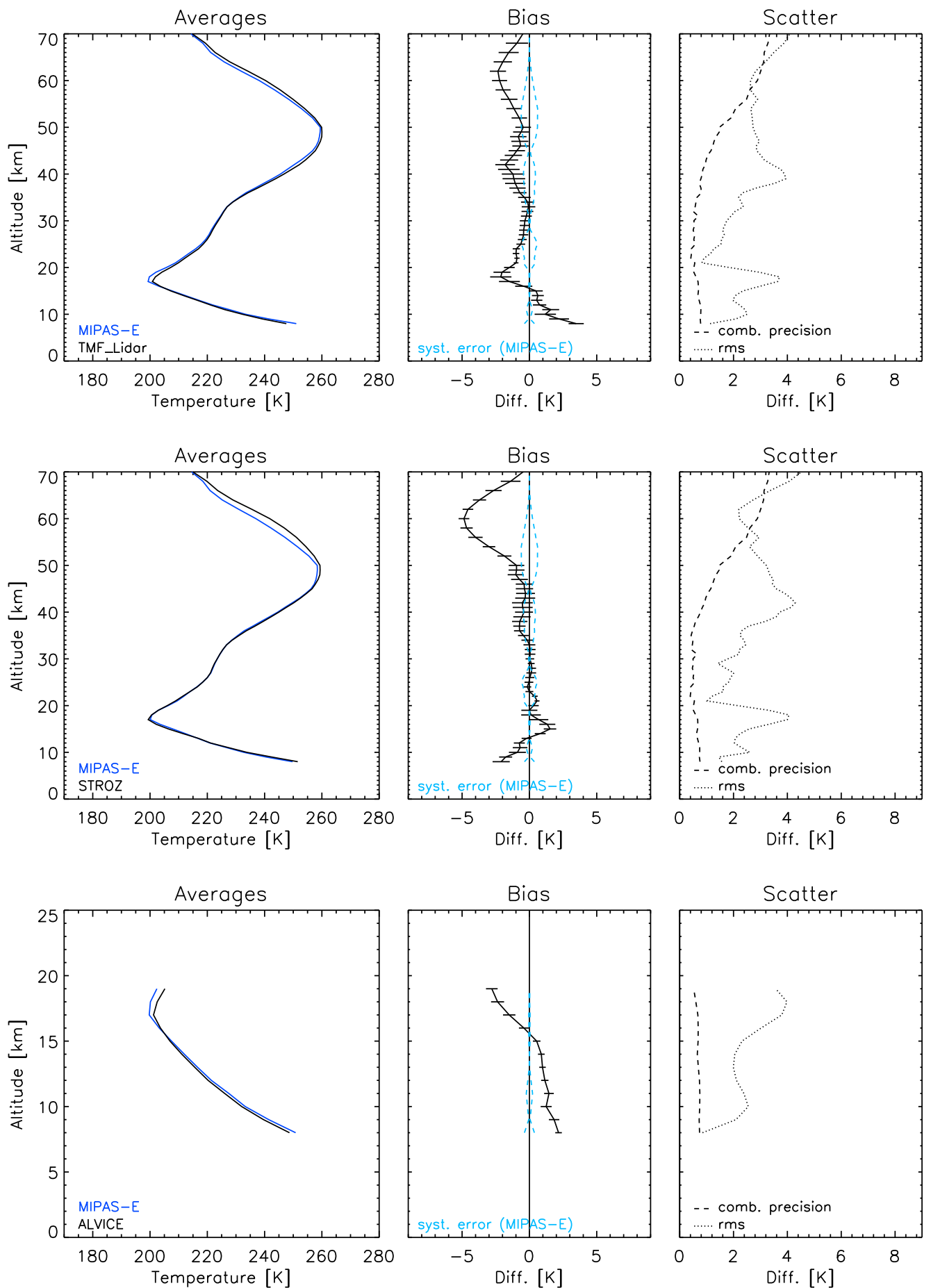

Fig. 2. Top row, left panel: average over all MIPAS temperature profiles (blue) for which coincidences with TMF lidar profiles have been found, together with the average of degraded TMF lidar profiles (black) which are coincident with the MIPAS profile. Top row, middle panel: averaged absolute differences together with their standard errors of the mean (error bars) and the combined systematic error components of the two measurements (dashed lines). Top row, right panel: bias-corrected root mean squares (rms) differences (dotted line) and the combined precisions of individual MIPAS and TMF lidar profiles (dashed line). Middle row: same as top row, but for STROZ lidar temperature profiles. Bottom row: same as top row, but for ALVICE lidar temperature profiles. 
(see Fig. 2, bottom row). The MIPAS systematic errors and the combined precisions are much smaller than the bias and the bias-corrected rms differences, respectively.

There is no clear explanation for the different behaviour of STROZ vs. TMF and ALVICE in the troposphere. STROZ data reveal a high bias of tropospheric temperatures compared to MIPAS, while TMF and ALVICE show a low bias. The ALVICE lidar is a different technique (Raman rotational) than STROZ and TMF, and is designed for tropospheric temperature recording. TMF and STROZ are designed for measurement of stratospheric and mesospheric temperature, and therefore are not so trustworthy well below the tropopause. Incomplete beam-telescope field-ofview overlap leads to temperature errors that can go both ways (i.e. too hot or too cold). Saturation effects may also impact the quality of the measurements. Finally, increasing aerosol optical thickness in the troposphere may be another source of error.

\subsubsection{Comparison to radiosonde temperatures}

The RS92 sondes flown together with the frost point hygrometers and ozonesondes provide accurate measurements of temperature up to about $30 \mathrm{~km}$. Comparison to single temperature profiles provided by the RS92 sondes flown together with the CFH frost point hygrometer (see Fig. 3, top row) show in general good agreement with MIPAS except some oscillations of the MIPAS temperature profiles with a period of $\sim 5 \mathrm{~km}$ which are not present in the RS92 - frost point hygrometer profiles. The deviations between pairs of single profiles, however, are mostly larger than the estimated total error of MIPAS. The mean differences (see Fig. 4, top row) reproduce the already known high bias below the tropopause $(\sim+1 \mathrm{~K}$ within $5 \mathrm{~km}$ distance of the tropopause to $+2.5 \mathrm{~K}$ below $10 \mathrm{~km}$ altitude) and low bias (1-2 K) just above the tropopause. The bias is considered significant below 15 and between 22 and $25 \mathrm{~km}$ and not explainable by known systematic errors of MIPAS. The bias-corrected rms differences are much larger than the estimated combined precisions, hinting towards a severe underestimation of the random errors of one or both instruments, or deviations introduced by natural variabilities within the spacial and temporal coincidence ranges. Similar differences are found in the comparison to the temperature data provided from RS92 flown together with the NOAA FPH (see Fig. 3, bottom row, and 4, bottom row), however with tropospheric differences of $+1 \mathrm{~K}$ to $+3 \mathrm{~K}$ instead of $+1 \mathrm{~K}$ to $+2.5 \mathrm{~K}$. A relative shift of the compared profiles in altitude by about $200 \mathrm{~m}$ would remove most of the differences, except the low bias of MIPAS directly above the tropopause.

Besides on the frost point hygrometer balloon flights, RS92 sondes were also flown individually and provided 44 (RS92_GSFC) and 81 (RS92_JPL) temperature profile measurements up to $30 \mathrm{~km}$ altitude coincident to MIPAS observations. A number of coincident single RS92_GSFC and
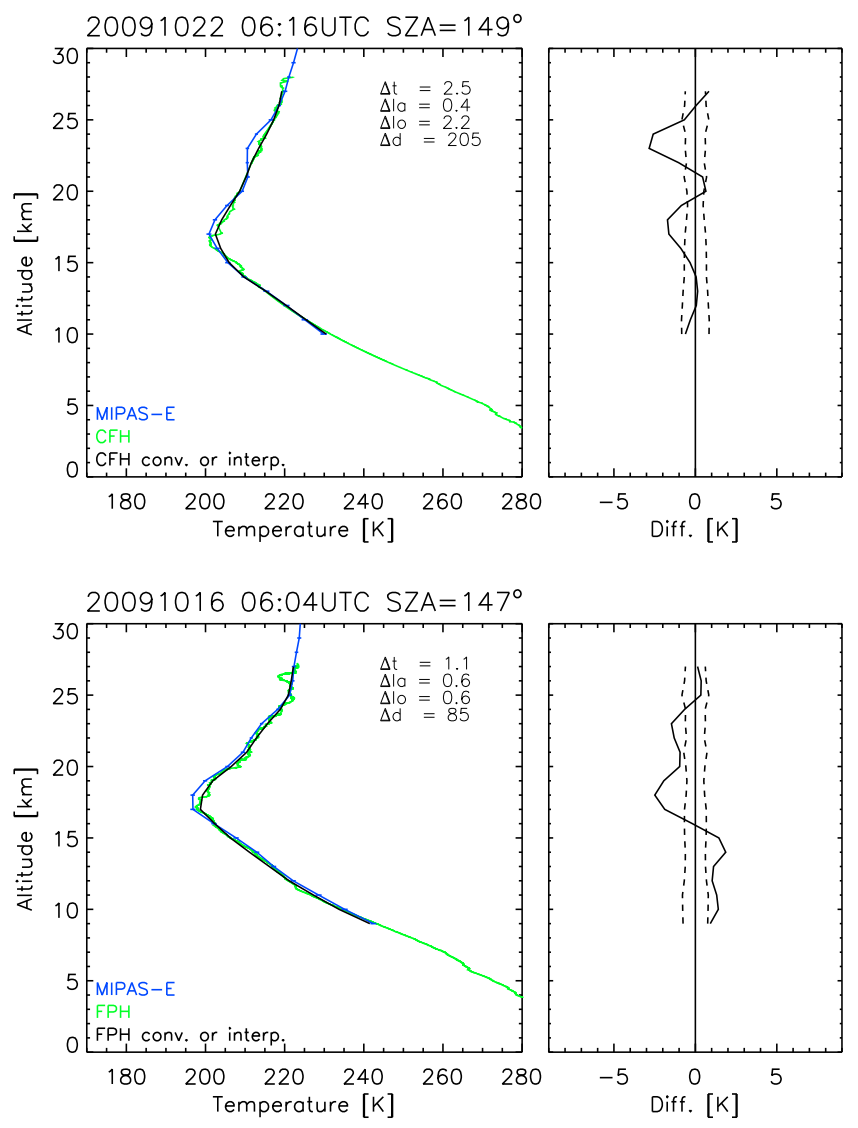

Fig. 3. Same as Fig. 1 but for RS92 radiosonde temperature profiles recorded during flights with the CFH (top) and NOAA FPH (bottom) frost point hygrometers. For a more detailed description see Fig. 1.

RS92_JPL profiles had physically unreasonable outliers in the upper part of the covered altitude range. These profiles have been removed manually on basis of visual inspection before calculating the mean differences. After removing the outlier profiles, the general picture of the RS92_GSFC / RS92_JPL - MIPAS temperature comparison is the same as found in the other comparisons: the high bias in the troposphere and low bias in the stratosphere of MIPAS temperatures is confirmed (see Fig. 6). The single differences oscillate rather strongly with values of 0 to $+3 \mathrm{~K}$ in the troposphere and -3 to $0 \mathrm{~K}$ in the stratosphere (see Fig. 5). Again, the bias-corrected rms differences are much larger than the estimated combined precisions, hinting at overly optimistic precision estimates or large natural variability.

\subsubsection{Comparison to temperatures from satellite instruments}

Within the period of the MOHAVE-2009 campaign coincidences with other satellite instruments providing temperatures were found for Aura/MLS, ACE-FTS, and AIRS. 

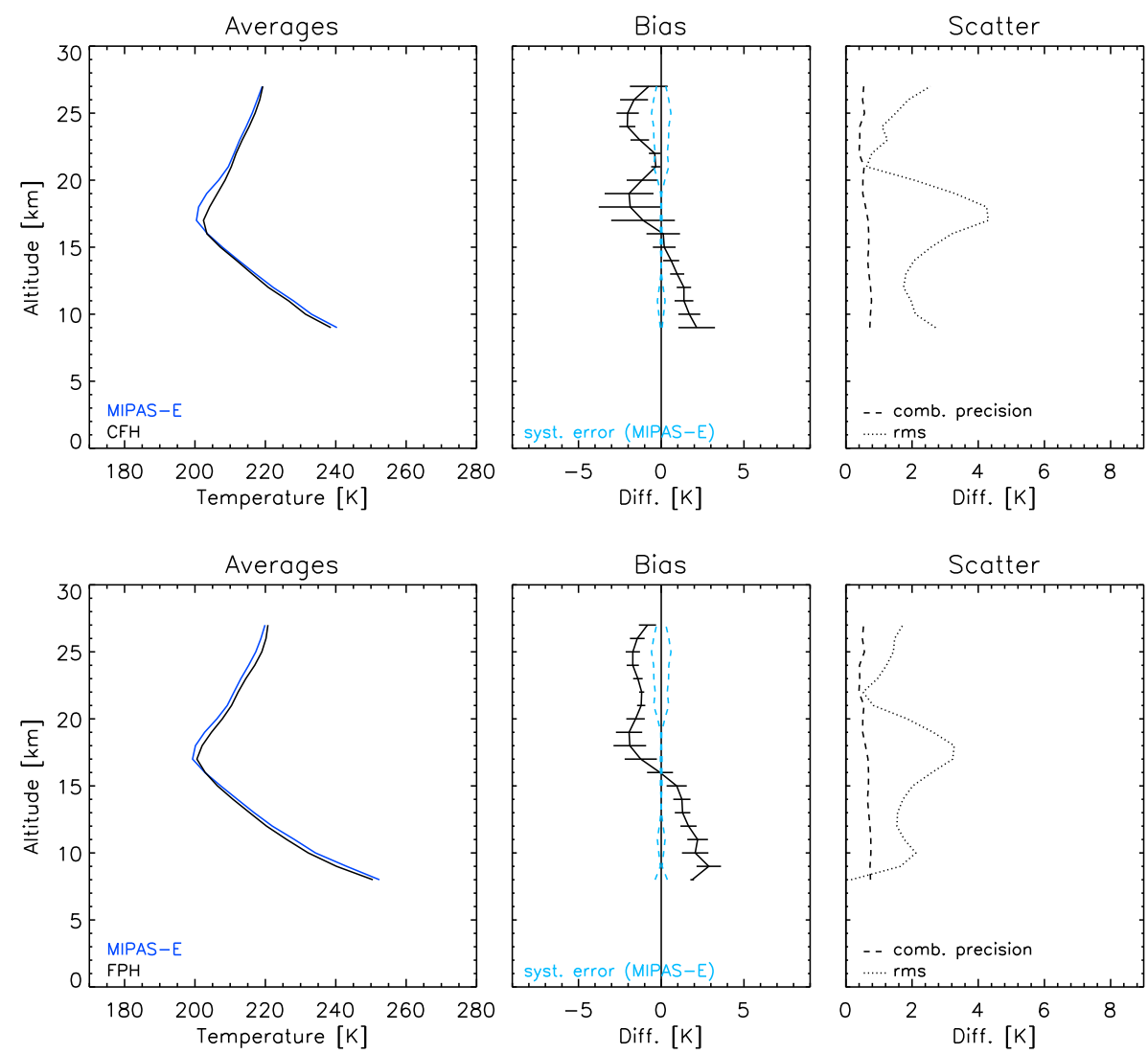

Fig. 4. Same as Fig. 2, but for RS92 radiosonde temperature profiles recorded during flights with the CFH (top row) and NOAA FPH (bottom row) frost point hygrometers. For a more detailed description see Fig. 2.

Coincidences were only searched for within $1000 \mathrm{~km}$ around the Table Mountain Facility. The number of coincidences for Aura/MLS and ACE-FTS were rather sparse (see Table 3), partly due to differing local overpass times, partly due to differing observation geometries. Nevertheless we provide here the average differences in temperature for MIPAS versus these three instruments.

The differences of MIPAS versus Aura/MLS (v3.3) mean temperatures provide a strong signature below the tropopause with MIPAS being warmer by up to $3 \mathrm{~K}$ in the troposphere; in contrast, MIPAS is colder than MLS in the stratosphere between 25 and $42 \mathrm{~km}$ with the low bias peaking at $37 \mathrm{~km}$ and reaching $-6 \mathrm{~K}$ (see Fig. 7, top row). The bias cannot be explained by the systematic error of MIPAS for most of the altitude range, and the estimated precison is about a factor of two to four lower than the bias-corrected rms, pointing towards underestimation of random errors.

The MIPAS versus ACE-FTS mean temperature differences oscillate within a band of $\pm 3 \mathrm{~K}$, with maximum deviations around 37 and $42 \mathrm{~km}(-3 \mathrm{~K}$ and $+3 \mathrm{~K}$, respectively), which, however, are not considered significant (the bias is not different from zero within its $1-\sigma$ uncertainty). Significant biases are found between 19 and $23 \mathrm{~km}$, and above
$50 \mathrm{~km}$ (see Fig. 7, middle row). The biases are larger than the estimated systematic errors of MIPAS. The bias-corrected rms differences are much larger than the estimated combined precisions of the two instruments up to the stratopause, but considerably smaller than the combined estimated precision above. The over-all structures of the two mean temperature profiles are consistent, although the stratopause seems to be lower by $2-3 \mathrm{~km}$ in the case of MIPAS which may partially explain the differences just below and above the stratopause. The AIRS mean temperature profile deviates from the MIPAS mean profile in the troposphere (MIPAS being higher by up to $3 \mathrm{~K}$ ), just above the tropopause (MIPAS being lower by $2 \mathrm{~K}$ ), around $30 \mathrm{~km}$ (MIPAS being lower by $2 \mathrm{~K}$ ), and in the stratopause (MIPAS being lower by $2 \mathrm{~K}$ ). Over all the stratosphere, MIPAS temperatures seem to be biased low versus AIRS temperatures by about $1 \mathrm{~K}$ on average (see Fig. 7 , bottom row), while in the troposphere, MIPAS is higher by about $2 \mathrm{~K}$. The deviations are larger than the systematic errors of MIPAS, and the combined precisions are lower than the bias-corrected rms differences which hints towards an underestimation of the precision. 

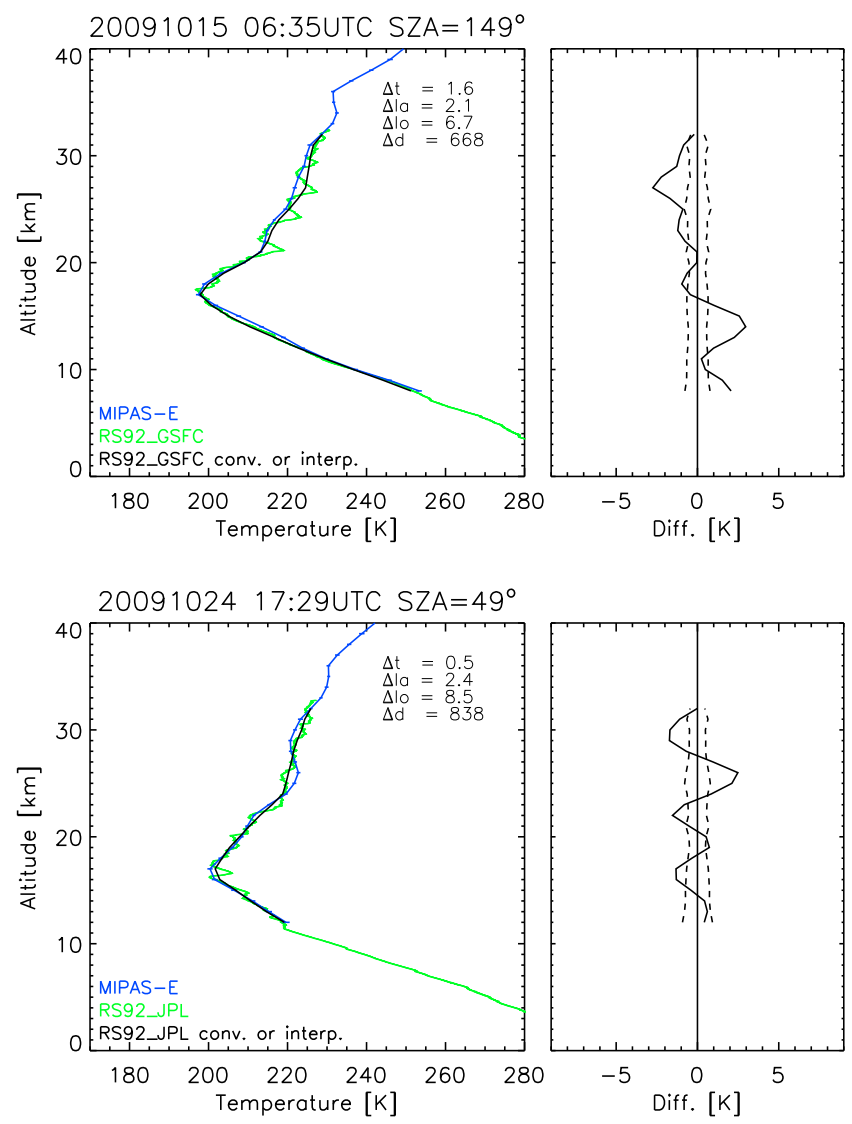

Fig. 5. Same as Fig. 1 but for RS92_GSFC (top) and RS92_JPL (bottom) radiosonde temperature profiles. For a more detailed description see Fig. 1.

\subsubsection{Non-LTE aspects}

The effect of non-LTE in the MIPAS temperature retrievals below 70 km over the Table Mountain Facility is not significant. This is because the population of the $15 \mu \mathrm{m}$ states from which the temperature is derived, mainly that of the $01^{1} 0$ vibrational level, is in or very close to LTE at mid-latitudes below $85-90 \mathrm{~km}$, even during daytime (López-Puertas and Taylor, 2001). The temperature error caused by the noninclusion of non-LTE is smaller than $0.2 \mathrm{~K}$ below $60 \mathrm{~km}$ and smaller than $0.5 \mathrm{~K}$ at $70 \mathrm{~km}$.

\subsection{Water vapor}

Water vapor was the main validation target of the MOHAVE2009 campaign. The goal of the MOHAVE-2009 campaign was to provide an accurate intercomparison of the instruments widely applied to measure water vapor from the ground or from balloons. We took this validation opportunity for comparison to the water vapor profiles derived from MIPAS.

\subsubsection{Comparison to lidar water vapor measurements}

The TMW lidar provides water vapor measurements from ground up to about $22 \mathrm{~km}$ for nightly mean profiles, while MIPAS gives information from about $6 \mathrm{~km}$ (or cloud top altitude) up to the lower mesosphere. An example for the comparison of a single MIPAS water vapor profile with a nightly mean TMW lidar observation on 17 October 2009 is shown in Fig. 8. The differences between the single MIPAS and the nightly mean TMW lidar water vapor profiles are within $10 \%$ above $13 \mathrm{~km}$, but reach $+50 \%$ below. Above $13 \mathrm{~km}$, the differences are smaller than the total estimated error of MIPAS.

For the averages over all coincidences (see Fig. 9, top row), the differences between MIPAS and the nightly mean TMW lidar profiles are within $10 \%$, except for the lowermost (below $\sim 13 \mathrm{~km}$ ) and uppermost (above $\sim 24 \mathrm{~km}$ ) altitude ranges, and especially the region around $10 \mathrm{~km}$ where the differences reach their maximum of $+30 \%$. At $14 \mathrm{~km}$ and above, the bias between MIPAS and TMW lidar can fully be explained by the systematic errors of MIPAS which are driven by the uncertainties of spectroscopic data. The biascorrected rms differences below $15 \mathrm{~km}$ are larger than the estimated combined precision which hints towards underestimation of the random errors or a very high natural variability; the latter often makes water vapor validation very difficult. In the stratosphere the bias-corrected rms differences are even smaller than the combined precison which hints towards overestimation of the random uncertainty of the data and might be considered as another hint that natural variability may play a significant role below this altitude.

The STROZ lidar covers water vapor up to about $22 \mathrm{~km}$; comparisons to MIPAS could be made up to $17 \mathrm{~km}$. As reported in Leblanc et al. (2011) and Whiteman et al. (2011), STROZ lidar water vapor measurements at high altitudes (low water vapor) are biased high due to undesired fluorescence, although a blocking filter was applied which greatly reduced, but did not completely remove the fluorescence (see Sect. 3.1.1). Leblanc et al. (2011) reported that the wet bias of STROZ water vapor data started at $10 \mathrm{~km}$ and reached $+20 \%$ above $15 \mathrm{~km}$. The MIPAS profiles are lower than STROZ by $-30 \%$ and more below $10 \mathrm{~km}$, and lower by $-15 \%$ to $-20 \%$ at $12 \mathrm{~km}$ and above (see Fig. 9, middle row) the latter being consistent with the former findings. The bias-corrected root mean squares differences are by far larger than the estimated combined precisions.

Similar to the STROZ water vapor profiles, the ALVICE water vapor profiles are restricted to altitudes below $22 \mathrm{~km}$; we compare here to the best estimate version of the profiles which has been corrected for a bias due to undesired fluorescence (see Sect. 3.1.1, Leblanc et al., 2011; Whiteman et al., 2011). The mean MIPAS water vapor profile above $10 \mathrm{~km}$ agrees within $8 \%$ with the corrected, so-called best estimate mean ALVICE profile while below $10 \mathrm{~km}$, MIPAS shows again a low bias. The bias-corrected rms differences 

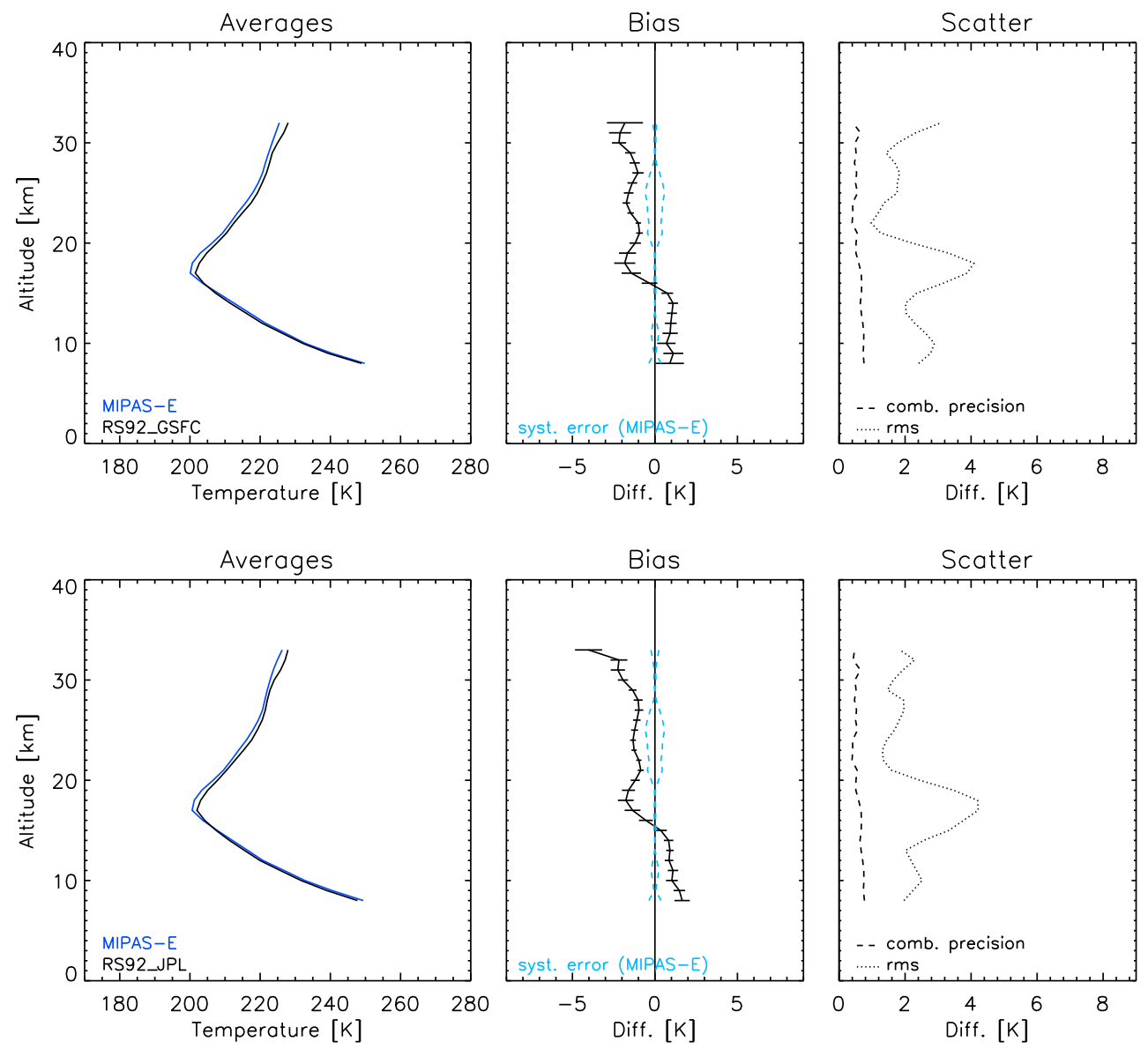

Fig. 6. Same as Fig. 2, but for RS92_GSFC (top) and RS92_JPL (bottom) radiosonde temperature profiles. For a more detailed description see Fig. 2.

agree roughly with the combined precision at the uppermost altitudes (above $\sim 15 \mathrm{~km}$ ) and are larger below (see Fig. 9, bottom row).

\subsubsection{Comparison to frost point hygrometer water vapor measurements}

The frost point hygrometers provide water vapor mixing ratio measurements of high precision and accuracy in the troposphere and lower stratosphere up to $\sim 30 \mathrm{~km}$. Deviations between CFH and MIPAS individual water vapor profiles are sometimes very small and indicate that MIPAS reproduces the structure of the water vapor profiles, especially the position and deepness of the tropopause, very well (see Fig. 10, top row). The sharp structure with the sudden drop of water vapor VMR around $10 \mathrm{~km}$, however, cannot be resolved by MIPAS, which is demonstrated by the $\mathrm{CFH}$ profile adjusted to the vertical resolution of MIPAS by applying its averaging kernel (black line), since the adjusted CFH profile is lower above and higher within the water vapor drop. But even compared to this degraded profile, MIPAS has a high bias below
$14 \mathrm{~km}$ which increases with decreasing altitudes. Comparison to single NOAA FPH profiles confirm the comparison to CFH (see Fig. 10, bottom row).

Figure 11, top row, shows the average over all MIPAS vs. CFH coincidences. Below appr. $13 \mathrm{~km}$ the differences exceed $+20 \%$, while in the tropopause region and above the mean profiles agree within -5 and $+8 \%$, and MIPAS reproduces very well the profile shape. Above $13 \mathrm{~km}$, the bias can fully be explained by the systematic errors of MIPAS, driven mainly by spectroscopic uncertainties. The bias-corrected rms differences and the estimated combined precisions are very close between 15 and $18 \mathrm{~km}$ and the estimated combined precision is even larger than the bias-corrected rms above, hinting towards a good error estimate of both instruments in this altitude range, and a too pessimistic precision estimate above $18 \mathrm{~km}$.

The comparison with the NOAA FPH reproduces in general the picture obtained from the $\mathrm{CFH}$ comparison, however, differences in the stratosphere are slightly higher and within -12 and $+5 \%$ (see Fig. 11, bottom row). The severe high 

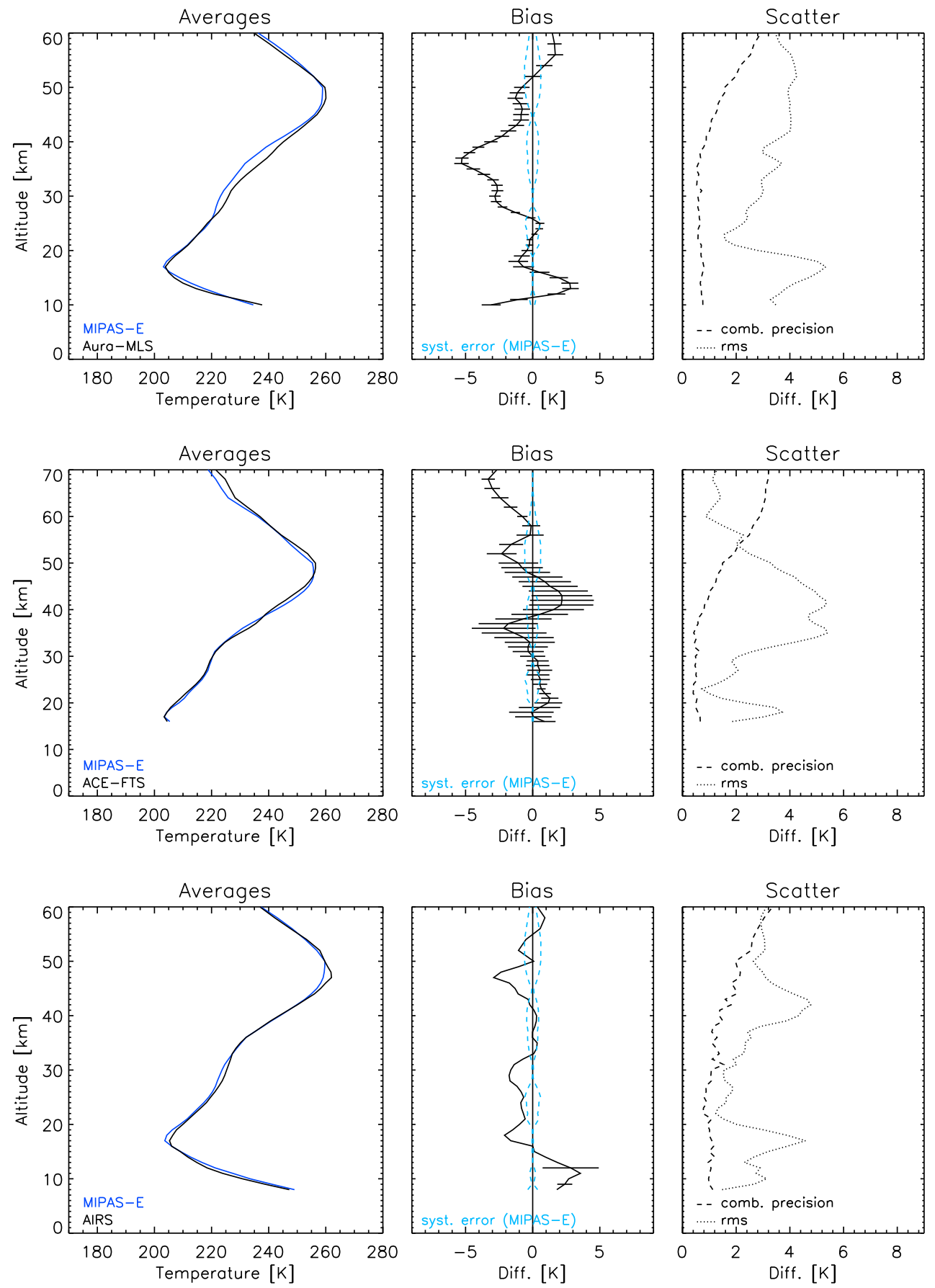

Fig. 7. Same as Fig. 2, but for Aura-MLS (top row), ACE-FTS (middle row), and AIRS (bottom row) temperature profiles. For a more detailed description see Fig. 2.

bias of MIPAS below $10 \mathrm{~km}$ is confirmed. The bias-corrected rms differences are reasonably close to the estimated combined precisions around $15-18 \mathrm{~km}$ and higher above, again pointing towards a too pessimistic precision estimate in the stratosphere.

\subsubsection{Comparison to microwave radiometer water vapor measurements}

Microwave radiometers operated from the ground generally provide a coarser altitude resolution in the stratosphere than MIPAS. For this reason, the MIPAS profiles have been 


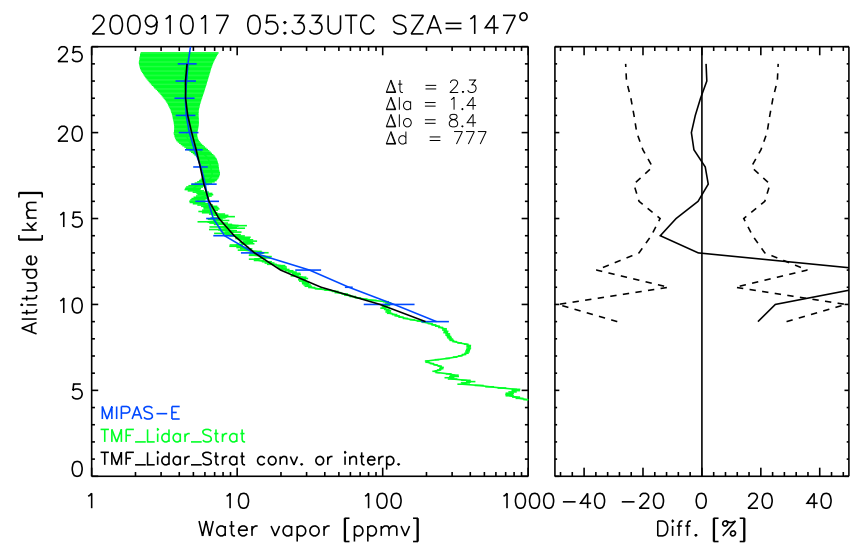

Fig. 8. Same as Fig. 1 but for TMW lidar water vapor profiles; the absolute water vapor VMRs are presented on a logarithmic scale, while the difference and the combined total errors are presented as percentage of the reference profile. For a more detailed description see Fig. 1.

degraded with the averaging kernels of the microwave instruments to adjust vertical resolution. The WVMS instrument provides water vapor measurements from about $26 \mathrm{~km}$ to the mesosphere. In the stratosphere, the MIPAS average profile starts to deviate positively from the WVMS average profile around $30 \mathrm{~km}$ and develops an increasingly high bias which peaks around $37 \mathrm{~km}$ with a value of $+10 \%$ (see Fig. 12, top row). A systematic low bias of WVMS in the stratosphere on the order of $-10 \%$ has been found in comparison to other instruments as well (Leblanc et al., 2011) which is consistent with the comparison to MIPAS. Right above the stratopause, the difference between MIPAS and WVMS becomes smaller, but a low bias of MIPAS in the order of $-8 \%$ is found a few kilometers above in the mesosphere which can be explained by the neglect of non-LTE-effects in the MIPAS retrievals (see Sect. 5.2.6). The deviations between the two average profiles are within the combined systematic errors everywhere. The bias-corrected rms differences and the combined precisions fit very well in the stratosphere, hinting towards a reliable error estimate of the instruments.

The MIAWARA-C instrument provides water vapor profiles from about $33 \mathrm{~km}$ to the mesosphere. MIPAS is lower than MIAWARA-C over all the comparison range, with a bias reaching $-10 \%$, except near $42 \mathrm{~km}$ where the bias is close to zero. Assuming an overall low bias of $-10 \%$ between WVMS and MIAWARA-C, the high bias of MIPAS around $40 \mathrm{~km}$ found in the comparison to WVMS is reproduced in relative terms by this comparison, and the low bias above $50 \mathrm{~km}$ due to neglecting non-LTE is also confirmed (see Fig. 12, bottom row). Again, the bias can fully be explained by the combined systematic errors of the two instruments, but the combined precisions are about twice the bias-corrected rms differences which hints towards an overestimation of the random errors.

\subsubsection{Comparison to water vapor profiles from the ground-based FTIR spectrometer MkIV}

Similar to the ground-based microwave instruments, the FTIR spectrometer MkIV operated from the ground provides a coarser altitude resolution than MIPAS, and MIPAS profiles have been adjusted with the MkIV averaging kernels to allow meaningful comparison of the instruments. The sensitivity of MkIV reaches from the ground to the upper troposphere $(\sim 15 \mathrm{~km}$, as provided by the averaging kernel), and the overlap range where both MIPAS and MkIV are sensitive often is small. Contrary to most of the frost point hygrometer and lidar instruments, the comparison of MIPAS to MkIV reveals a strong negative bias of MIPAS of up to $-30 \%$ at altitudes below $15 \mathrm{~km}$ (see Fig. 13). Furthermore, the bias-corrected root mean squares differences are much larger than the combined precisions. This is inconsistent with the MOHAVE 2009 MkIV-RS92 comparison of Schneider et al. (2010), which showed good agreement between MkIV and the corrected Vaisala RS92 sondes. It should be kept in mind, however, that our formalism according to Eq. (4) and its variants disregards any a priori content of the better resolved profile (in this case MIPAS), which might not be fully appropriate in the upper troposphere.

\subsubsection{Comparison to water vapor measurements from satellite instruments}

Comparison to other satellite instruments suffer from the few available coincidences found during the period of the MOHAVE-2009 campaign, and a satellite intercomparison would be better done globally. Nevertheless, we include here the coincidences found for October 2009 within $1000 \mathrm{~km}$ around Table Mountain Facility, to make intercomparison of all instruments possible. We have found 43 coincidences between MIPAS and Aura/MLS which is mainly due to the different overpass times and a temporal coincidence criterion of $4 \mathrm{~h}$ (similar to the other comparisons). We have used Aura/MLS version 3.3 data for the comparison. Despite the sparse coincidences, the two instruments show good agreement, particularly in the stratosphere (see Fig. 14, top row) where the bias is between -6 and $+10 \%$ which can be fully explained by the combined systematic errors of the profiles. Below the hygropause the bias between MIPAS and MLS oscillates within $\pm 20 \%$, while in the mesosphere, the wellknown low bias of MIPAS is confirmed by the MLS observations. The combined precision is larger then the biascorrected rms above $13 \mathrm{~km}$ which hints towards an overly pessimistic random error estimate.

Although coincidences between MIPAS and ACE-FTS are sparse, the comparison between the two instruments provides a picture consistent with the other comparisons (see Fig. 14, middle row). The two instruments cover a similar altitude range from the upper troposphere to the lower mesosphere. Average deviations between the two mean water 

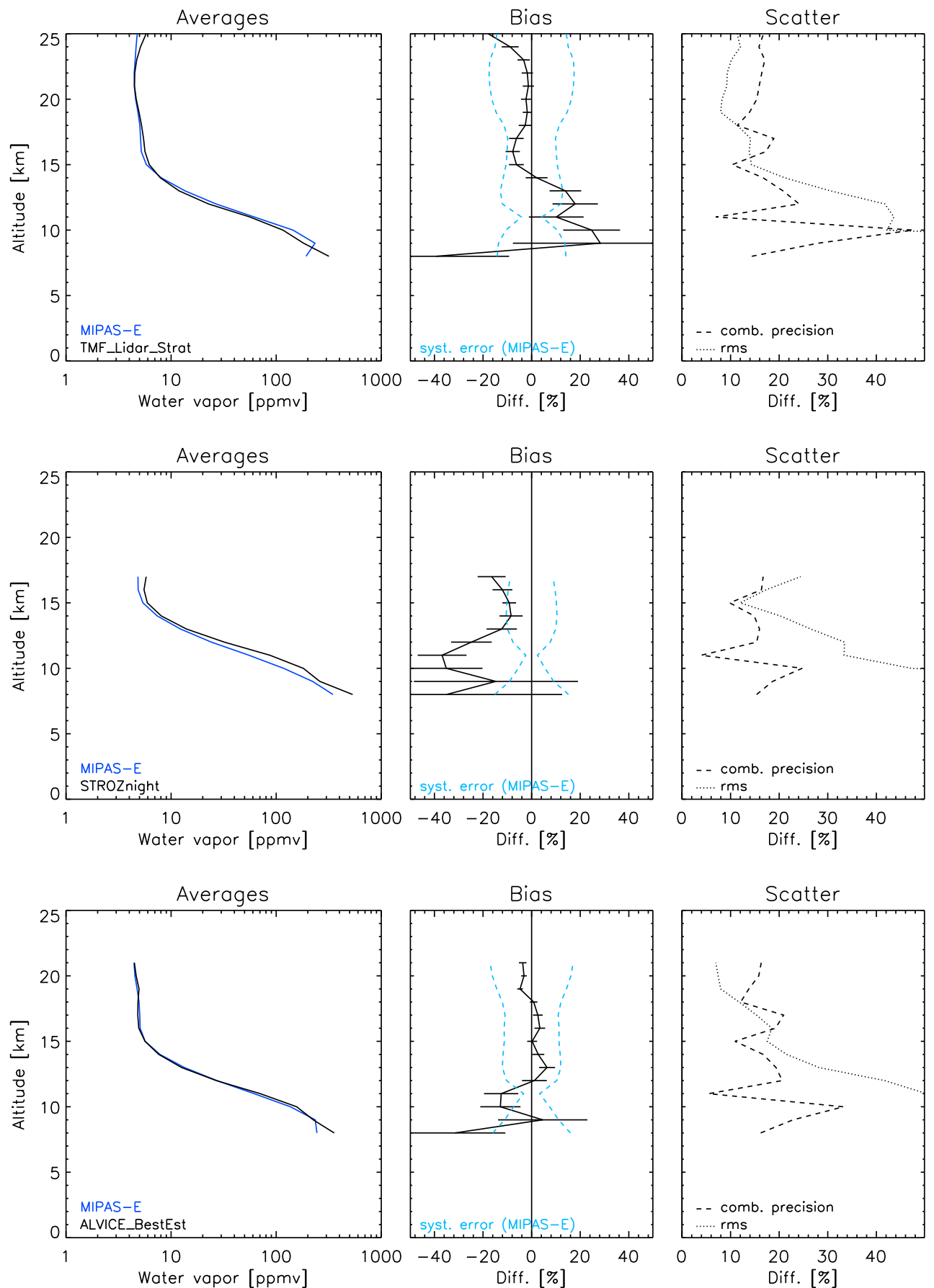

Fig. 9. Same as Fig. 2 but for water vapor profiles from TMW lidar (top row), STROZ lidar (middle row), and ALVICE lidar (bottom row); the absolute water vapor VMRs are presented on a logarithmic scale, while the bias and the various errors and bias-corrected rms differences are presented as percentage of the average reference profile. For a more detailed description see Fig. 2.

vapor measurements are over all well below $\pm 10 \%$ except below $15 \mathrm{~km}$, where differences reach -20 to $-25 \%$, and above $60 \mathrm{~km}$, caused by the non-inclusion of non-LTE in our MIPAS retrievals. It is to be noted that this is one of only few comparisons, besides MkIV and the lidars STROZ and ALVICE, where MIPAS is biased low in the troposphere. The estimated combined precisions again are higher than the bias-corrected rms differences and confirm the finding of an overly pessimistic precision estimate in the stratosphere. 

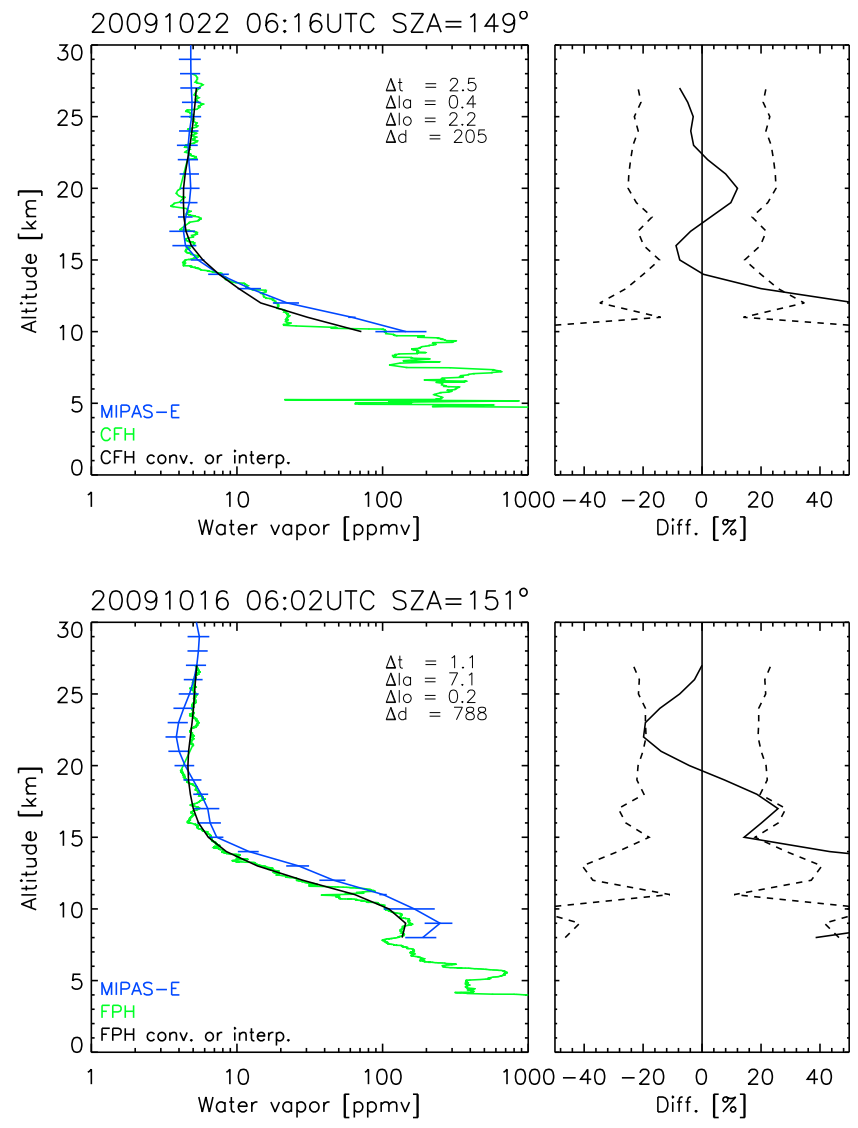

Fig. 10. Same as Fig. 8 but for CFH (v3.20, top row) and NOAA FPH (bottom row) frost point hygrometer profiles of water vapor. For a more detailed description see Fig. 8.

AIRS retrieves water vapor between the surface and $100 \mathrm{hPa}$, though sensitivity is low for mixing ratios of about 10 ppmv or less (Gettelman et al., 2004; Fetzer et al., 2008). Since this is the lower part of the MIPAS observations, comparison is somewhat difficult, despite the high number of coincidences found. The bias between MIPAS and AIRS varies between $\pm 10 \%$ and can be explained by the systematic errors of MIPAS, however, it is mostly not significant because of its large standard error (see Fig. 14, bottom row). The uppermost data point of the comparison is just at the edge of the sensitivity range of AIRS and should therefore be taken with some caution. Both the estimated combined precision and the bias-corrected rms are large, with the combined precision being about twice the bias-corrected rms, which hints towards an overestimation of the random errors.

\subsubsection{Non-LTE aspects}

The effects of non-LTE on the water vapor retrieval at midlatitudes are more important than on kinetic temperature. The daytime populations of the water vapor (010) vibrational level, from which water vapor abundance is retrieved, departs from LTE as low as $60 \mathrm{~km}$. This is due to the strong coupling of that level with the $\mathrm{O}_{2}(1)$ level, which is populated after ozone photolysis. That produces water vapor (010) populations larger than in LTE. The strong water vapor fundamental band lines used in our retrievals are still at these altitudes under an optically thick regime. Instead of increasing the local water vapor abundance around $60 \mathrm{~km}$, the global fit technique used in the water vapor retrieval compensates the smaller radiance simulated with the lower LTE populations at that tangent height by decreasing the water vapor abundance at altitudes above, reducing that way the absorption along the line of sight. Figure 15 shows the effect on the retrieved daytime water vapor at mid-latitudes if the non-LTE effects are included. The figure presents the mean difference of about 100 profiles retrieved from MIPAS nominal mode measurements with and without taking non-LTE into account in the retrieval. The MIPAS LTE retrievals underestimate water vapor by $20 \%$ at $70 \mathrm{~km}, 8 \%$ at $60 \mathrm{~km}$ and overestimate it by $5 \%$ at $45-50 \mathrm{~km}$. Opposite to the behavior above $60 \mathrm{~km}$, the LTE retrieval at lower altitudes responds to the reduced absorption along the light of sight by increasing the abundance at that altitude. Although of systematic nature, the error due to neglect of non-LTE effects in the retrieval cannot be easily corrected, since this correction would depend on illumination (non-LTE excitation), the actual kinetic temperature profiles, and the actual amounts of other atmospheric constituents, and would thus not be constant for different atmospheric conditions.

In summary, these non-LTE effects on the water vapor retrievals can explain the differences found with other instruments in the lower mesosphere and also half of the difference found in the upper stratosphere. The rest of the difference in the upper stratosphere is in most cases anti-correlated with differences in the kinetic temperature, thus, the latter are their most likely source.

\subsection{Ozone}

\subsubsection{Comparison to lidar ozone measurements}

The lidar instruments provide ozone measurements from the upper troposphere to about $45 \mathrm{~km}$, while MIPAS measurements reach up to $70 \mathrm{~km}$ in the nominal observation mode. At TMF two lidars are operated optimized for measurement of tropospheric and stratospheric ozone, respectively. For more details, see Sect. 3.1.1 and Leblanc et al. (2011). The comparison of MIPAS mean ozone profiles to stratospheric ozone measurements by the TMF lidars is shown in Fig. 16, top row. A peak in the MIPAS profile around $37 \mathrm{~km}$ with positive deviations of $0.7 \mathrm{ppmv}$ is obvious, while the other parts of the tropospheric and stratospheric profiles agree within 0.3 ppmv. The deviations between MIPAS and the TMF lidar are within the range of the combined systematic errors. The combined precisions, however, are smaller 

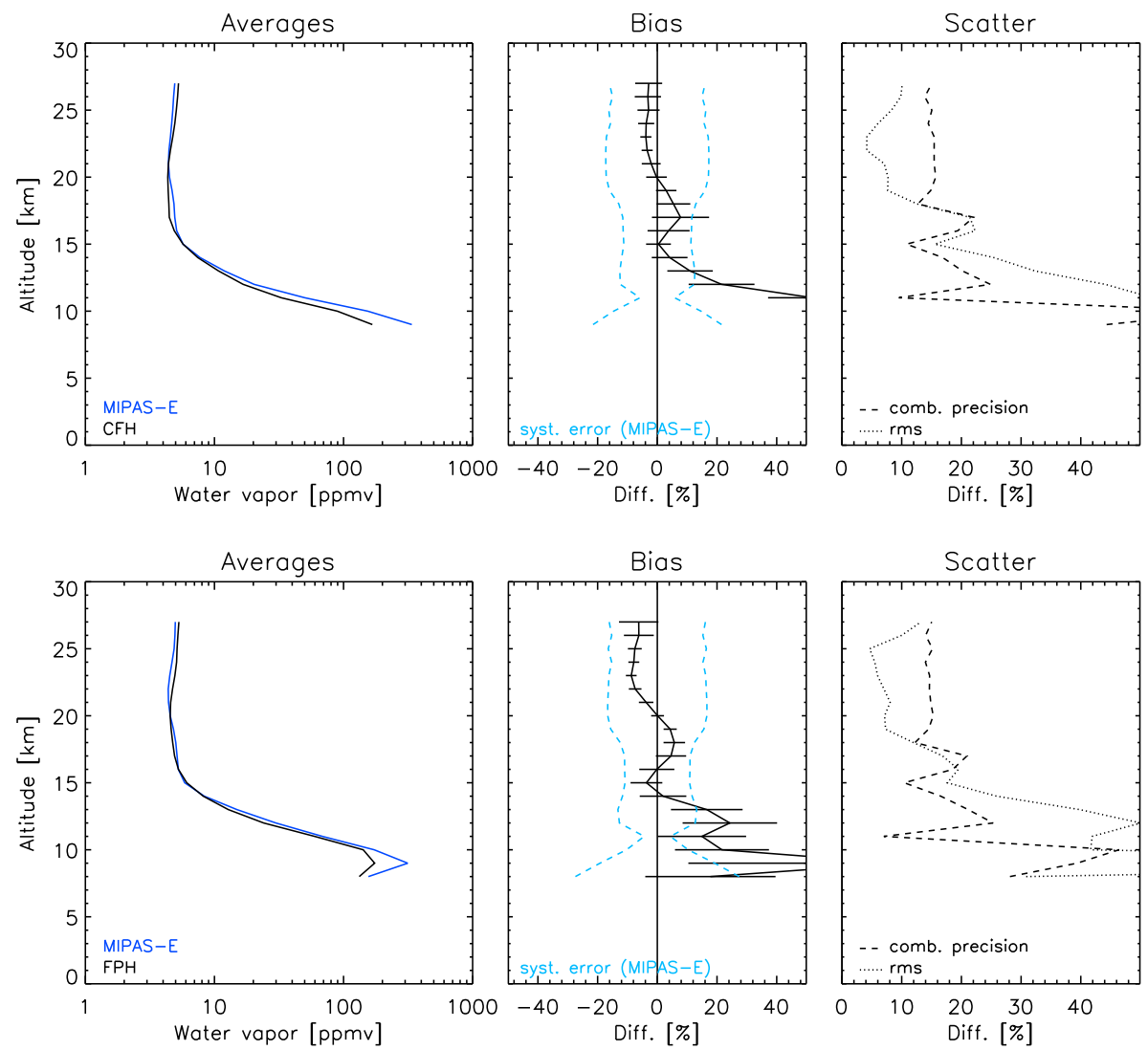

Fig. 11. Same as Fig. 9 but for CFH v3.20 (top row) and NOAA FPH (bottom row) frost point hygrometer profiles of water vapor. For a more detailed description see Fig. 9.

than the bias-corrected rms differences above $25 \mathrm{~km}$, but in agreement below. The tropospheric ozone measurements by the TMF lidars are shown in Fig. 16, middle row, together with the MIPAS profiles. The agreement is very good and does not exceed the combined systematic errors, while the bias-corrected rms differences are somewhat larger than the combined precisions. Both the stratospheric and the tropospheric TMF lidar ozone measurements hint towards an oscillation in the MIPAS profiles with maximum values around 22 and minimum values around $27 \mathrm{~km}$ with a peak-to-peak amplitude of $0.3 \mathrm{ppmv}$, which, however, does not exceed the estimated systematic errors of MIPAS.

The STROZ lidar provides ozone measurements between approx. 15 and $45 \mathrm{~km}$; comparison of the STROZ mean profiles to MIPAS mean profiles is shown in Fig. 16, bottom row. The comparison is consistent with the findings from TMF lidar: MIPAS ozone has a bulge with high ozone values around $37 \mathrm{~km}$ which, however, is still within the estimated systematic error. The positive bias of MIPAS reaches +0.9 ppmv at $37 \mathrm{~km}$ and remains below \pm 0.3 ppmv for all other altitudes below $45 \mathrm{~km}$. The oscillation in the difference profile with a maximum at 20 and a minimum at $27 \mathrm{~km}$ shows up in the comparison to STROZ as well, again with a peak-to-peak amplitude of about 0.3 ppmv. The bias-corrected rms differences are about twice as large as the estimated combined precisions above $25 \mathrm{~km}$ which hints towards underestimation of the random errors for one or both instruments.

\subsubsection{Comparison to ozonesonde measurements flown with the frost point hygrometers}

The ozone data provided with the frost point hygrometer measurements are from ozonesondes that were flown together with the frost point hygrometers. There are no differences between the ozonesondes flown with NOAA FPH and $\mathrm{CFH}$, so in principle the results from $\mathrm{CFH}$ and NOAA FPH balloon flights could be combined. We have kept them separate in order to follow the general scheme of comparisons to all instruments. The ozonesondes flown with the frost point hygrometers provide ozone measurements below $\sim 30 \mathrm{~km}$. As expected, the results from the comparisons to CFH and NOAA FPH are rather similar. MIPAS mean ozone profiles agree very well with the mean profiles of the ozonesondes, with an overall negligible bias, but an oscillation in the difference profile with maximum at 20 and minimum at $24 \mathrm{~km}$ (see Fig. 17). The amplitudes of the 

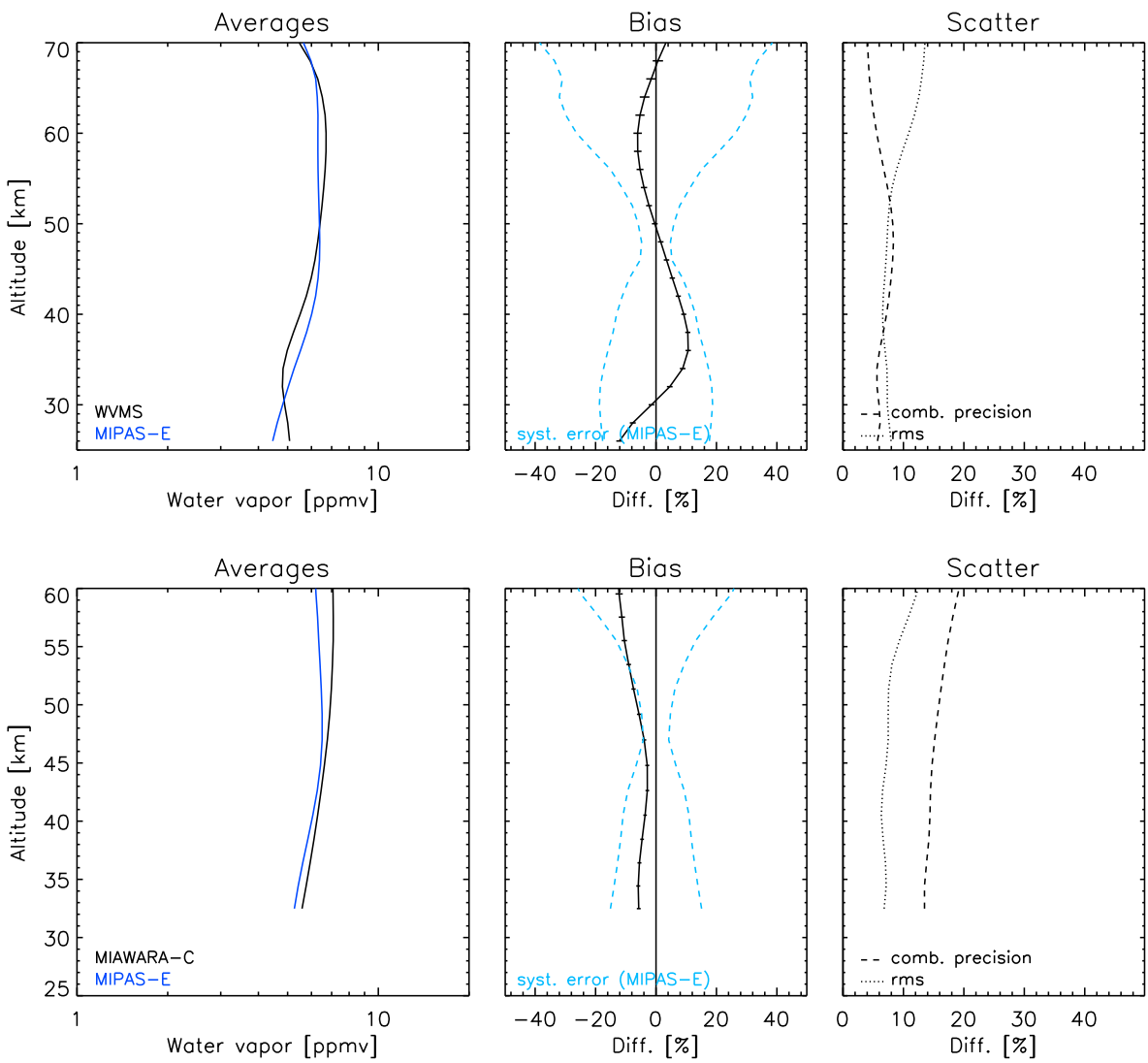

Fig. 12. Same as Fig. 9 but for WVMS (top row) and MIAWARA-C (bottom row) microwave radiometer water vapor profiles (6h measurement time). For a more detailed description see Fig. 9.
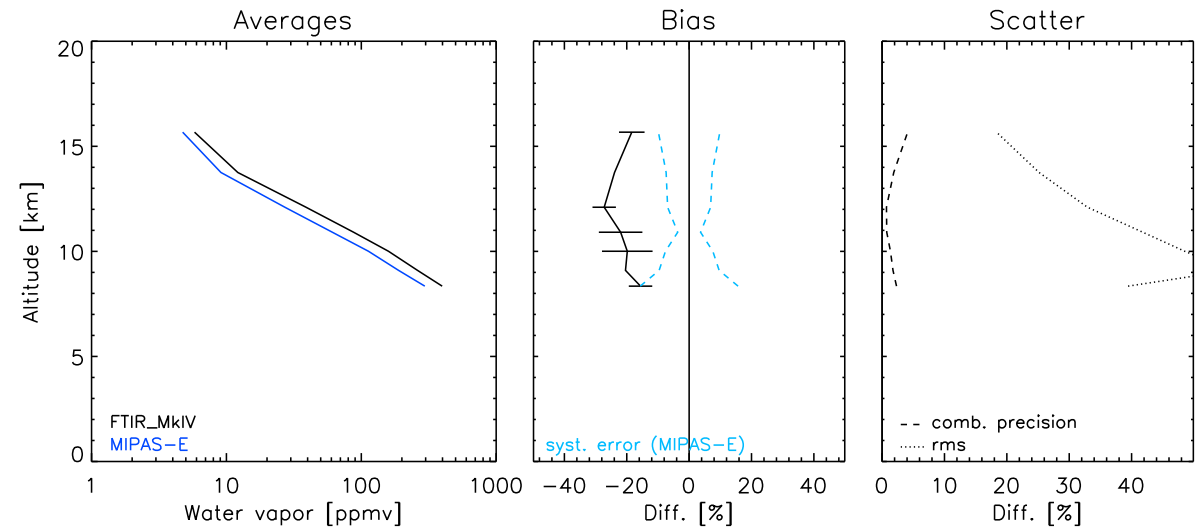

Fig. 13. Same as Fig. 9 but for MkIV FTIR spectrometer water vapor profiles. For a more detailed description see Fig. 9.

oscillations are different: they remain below $\pm 0.25 \mathrm{ppmv}$ in case of CFH (Fig. 17, top row), and below +0.15 and -0.2 ppmv in case of NOAA FPH (Fig. 17, bottom row) which might be due to differences in the actual spatial and temporal mis-matches between MIPAS measurements and the balloon flights. The estimated combined precisions are in both cases considerably smaller than the bias-corrected rms differences between 15 and $24 \mathrm{~km}$, which is a hint towards underestimated random errors. 

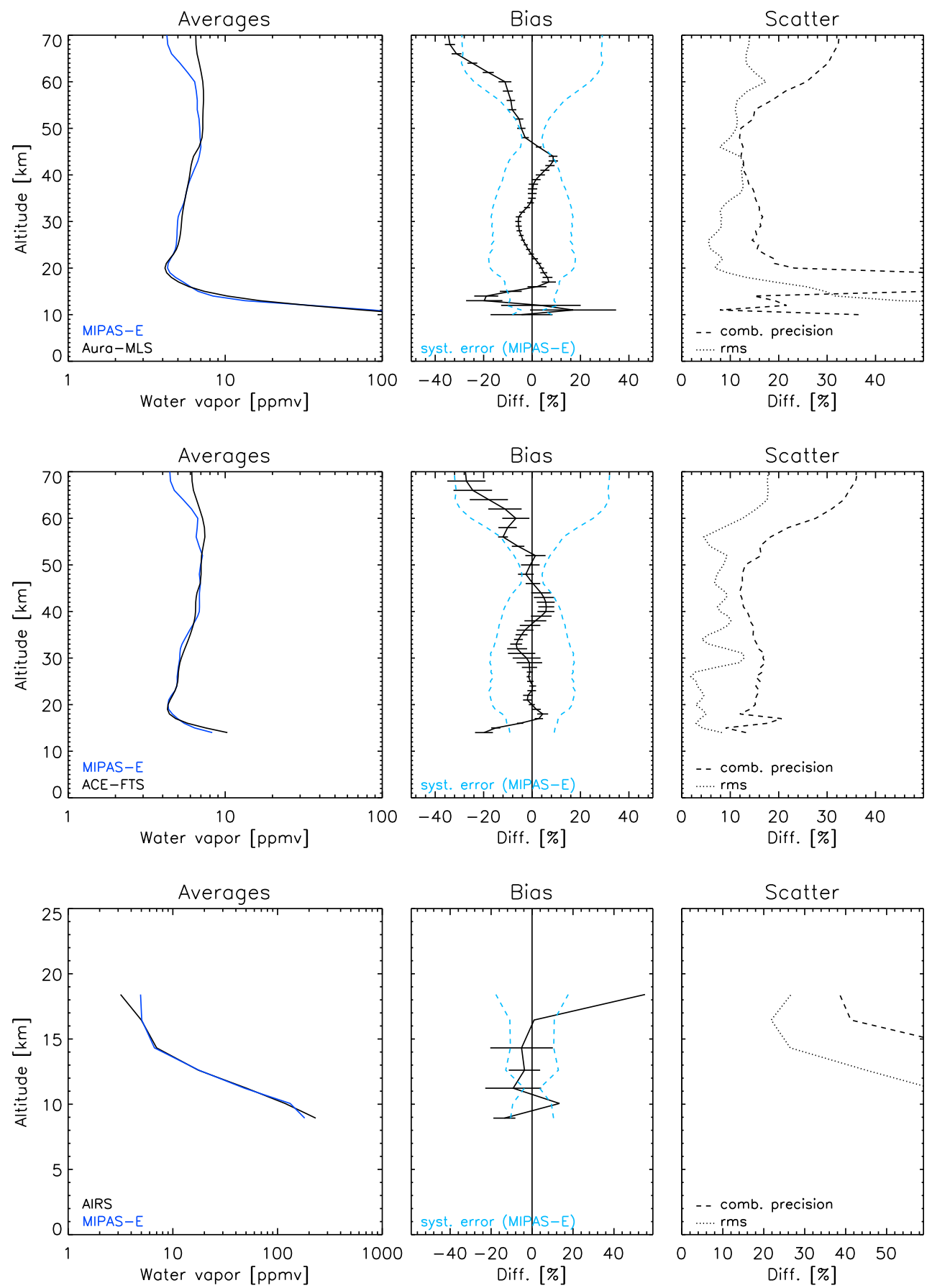

Fig. 14. Same as Fig. 9 but for water vapor profiles from Aura/MLS v3.3 (top row), ACE-FTS (middle row), and AIRS (bottom row). For a more detailed description see Fig. 9.

\subsubsection{Comparison to ozone profiles from satellite instruments}

From the satellite instruments, Aura/MLS, ACE-FTS, and AIRS provide ozone. The AIRS profiles, however, were found to be a scaled a priori profile only without providing information on the specific profile shape. For this reason, we compare to Aura/MLS and ACE-FTS only. The mean ozone profiles of Aura/MLS and MIPAS have rather different shapes. They agree reasonably well, with deviations of less than $\pm 0.3 \mathrm{ppmv}$, below $30 \mathrm{~km}$, but have different shapes around the ozone VMR maximum; in particular, the 


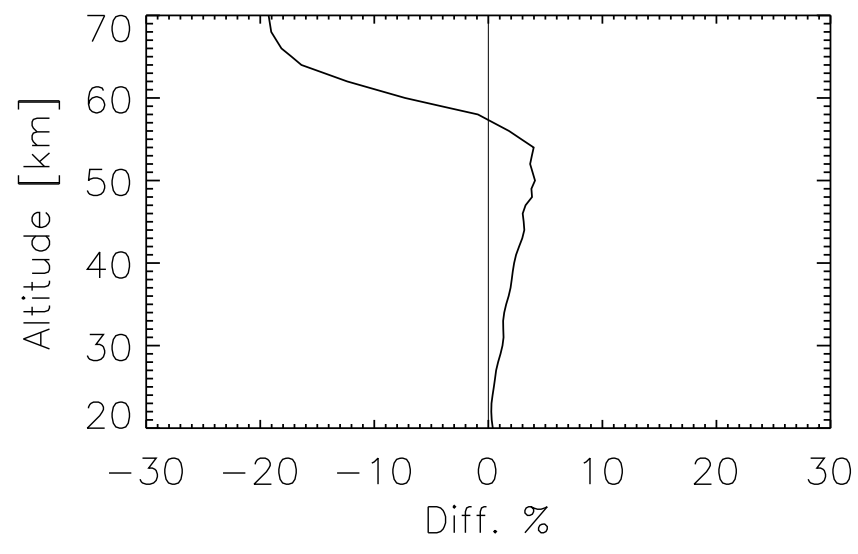

Fig. 15. Mean difference between MIPAS LTE and non-LTE water vapor daytime retrievals at mid-latitudes. About 100 profiles have been averaged.

bulge in MIPAS profiles around $37 \mathrm{~km}$ shows up here, too (see Fig. 18, top row). Above the stratospheric ozone VMR maximum, the profiles are more or less parallel, but shifted in altitude by $3 \mathrm{~km}$ and more. Resulting deviations above $30 \mathrm{~km}$ are in the order of -0.8 and $+1.2 \mathrm{ppmv}$ which is no longer explainable by the MIPAS systematic errors. The bias-corrected rms differences and the estimated combined precision are close below $25 \mathrm{~km}$ and above $35 \mathrm{~km}$, while in between the bias-corrected rms differences are larger.

The mean ozone profiles of MIPAS and ACE-FTS agree quite well in shape (see Fig. 18, bottom row); the differences reveal similar features as found in the comparison to lidar instruments: a positive bias of MIPAS peaking at $37 \mathrm{~km}$ and exceeding the systematic error estimate of MIPAS, a negative bias reaching $-0.5 \mathrm{ppmv}$ above, and some oscillating structures, although less pronounced, around 20 and $24 \mathrm{~km}$. ACEFTS ozone is known to be biased high between 45 and $60 \mathrm{~km}$, although reduced in version 3 from the version 2.2 ozone update, which explains the difference between MIPAS and ACE-FTS in this altitude range. The bias-corrected rms differences and the estimated combined errors agree well above $39 \mathrm{~km}$ and below $22 \mathrm{~km}$, while in between the precision error seems to be underestimated or the natural variability was large.

\subsubsection{Non-LTE aspects}

The ozone retrieval microwindows cover emissions from the $v_{2}$ and the $v_{3}$ levels, in particular, from the fundamental and first hot bands. Their populations depart from LTE above 60$65 \mathrm{~km}$ during daytime, mainly due to the recombination of molecular and atomic oxygen, which produces vibrationally excited ozone. The ozone overestimation due to neglecting non-LTE is smaller than $1 \%$ below $55 \mathrm{~km}$ and increases to $20 \%$ around $65-70 \mathrm{~km}$ (Gil-López, 2006). Since MIPAS ozone profiles are lower than the correlative measurements in the mesosphere, neglect of non-LTE in the MIPAS retrievals cannot explain the differences.

\section{Conclusions}

MIPAS measurements of temperature, water vapor and ozone from the upper troposphere to the lower mesosphere retrieved from level-1b so-called optimized-resolution spectral data (version 4.67) with the IMK/IAA processor have been compared to balloon-borne and in-situ measurements performed during the MOHAVE-2009 campaign at Table Mountain Facility, California in October 2009, and to co-located satellite instruments. The coincidence criteria were $1000 \mathrm{~km}$ in distance and $4 \mathrm{~h}$ between the co-located measurements. All coincidences between MIPAS profiles and correlative measurements were considered. We analysed both individual pairs of profiles and averages over all coincidences. We compared the mean difference profiles to their standard errors and the estimated combined systematic error in order to detect significant biases not explained by known systematic error sources. Further we compared the bias-corrected rms differences to the estimated combined precisions in order to judge if the precision estimates were realistic.

\subsection{Synopsis from all instruments: temperature}

The temperature comparisons with most instruments provided a consistent picture: in the stratosphere, no significant bias was detected. Both the altitude and the amplitude of the stratopause is well captured by MIPAS. Comparison with the TMF lidar and AIRS hint towards a low bias of MIPAS of $\sim-1 \mathrm{~K}$ throughout the stratosphere, however, this bias is not significant over wide parts of the profile and was not confirmed by other instruments. Comparison to MLS temperature profiles do not agree with the consistent picture from the other instruments: MLS has a pronounced high bias versus MIPAS in the tropopause and is further biased high between 25 and $42 \mathrm{~km}$. Differences in temperatures may propagate to species retrievals: MIPAS and MLS water vapor differences seem to be anti-correlated to differences in their temperatures; temperature differences could also explain the larger differences in ozone found between MIPAS and MLS in the stratosphere. Around the tropopause, MIPAS has revealed a high bias on the order of $2 \mathrm{~K}$ below the tropopause, and a low bias of the same amount in the lowermost stratosphere. This behaviour has been suspected before from comparisons with ECMWF analysis data where it occured in the subtropics only. Further down in the troposphere, most instruments indicate that the high bias of MIPAS remains between 1 and $2 \mathrm{~K}$, while STROZ and MLS indicate a low bias of about $2 \mathrm{~K}$. In the mesosphere, no consistent picture could be gained, but there is a tendency of MIPAS temperatures being too low around $60 \mathrm{~km}$. The mean difference profiles between MIPAS 

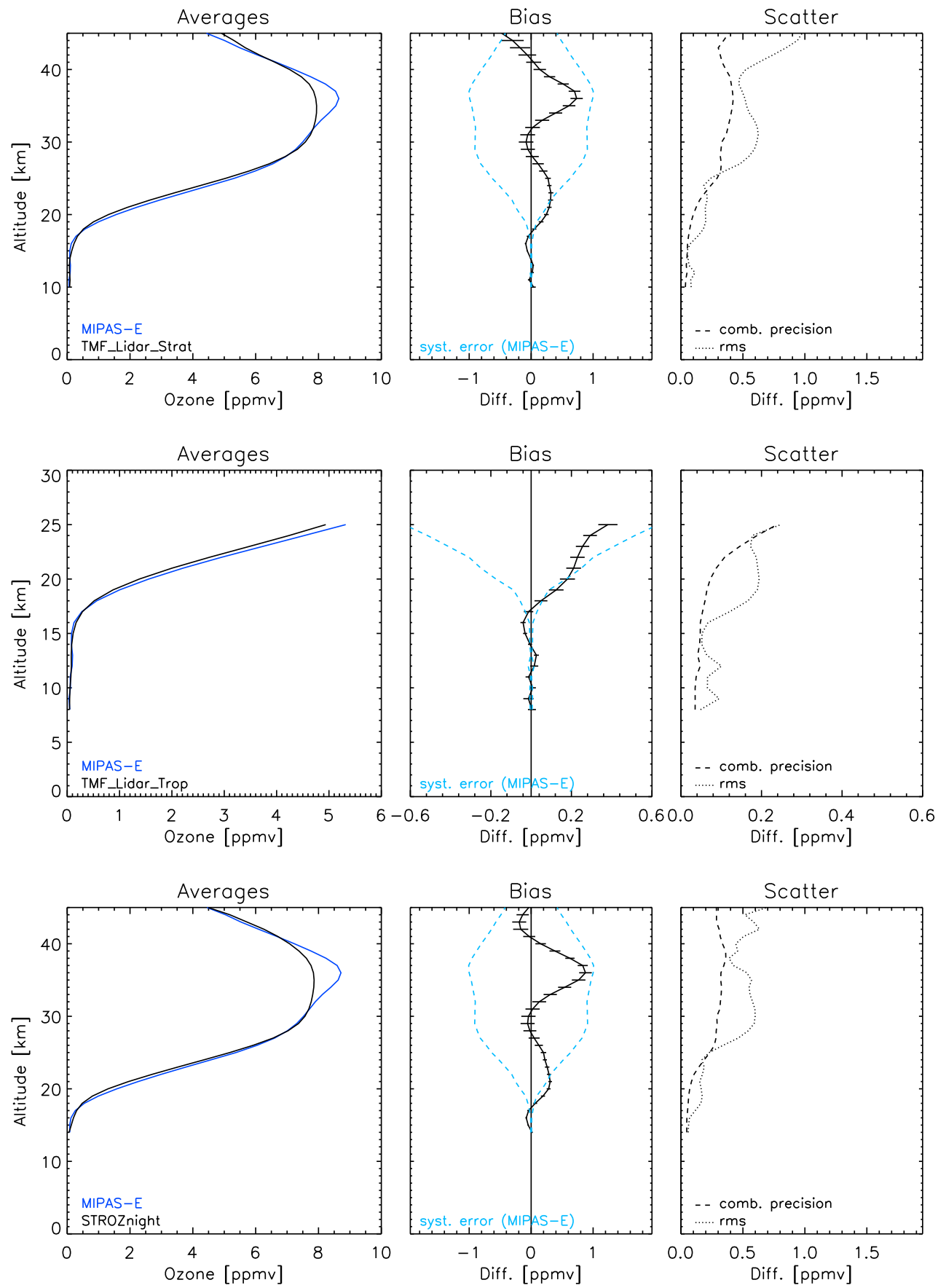

Fig. 16. Same as Fig. 2, but for the stratospheric TMF lidar ozone profiles (nightly means) (top row), the tropospheric TMF lidar ozone profiles (nightly means) (middle row), and STROZ ozone profiles (nightly means) (bottom row). For a more detailed description see Fig. 2.

and all other instruments, together with their standard errors, are compiled in Fig. 19, top panel.

The detected bias profiles are in general larger than the estimated systematic error profiles, i.e. the bias cannot be explained by known systematic uncertainties which are driven by spectroscopic uncertainties in case of MIPAS. The bias- corrected rms differences are typically between 2 and $3 \mathrm{~K}$ with a pronounced maximum around $17 \mathrm{~km}$ reaching values up to $5 \mathrm{~K}$. In particular the latter indicates that part of the bias-corrected root mean squares difference may come from high natural variability within the coincidence radii (in space and time). Leblanc et al. (2011) (their Fig. 8) and 

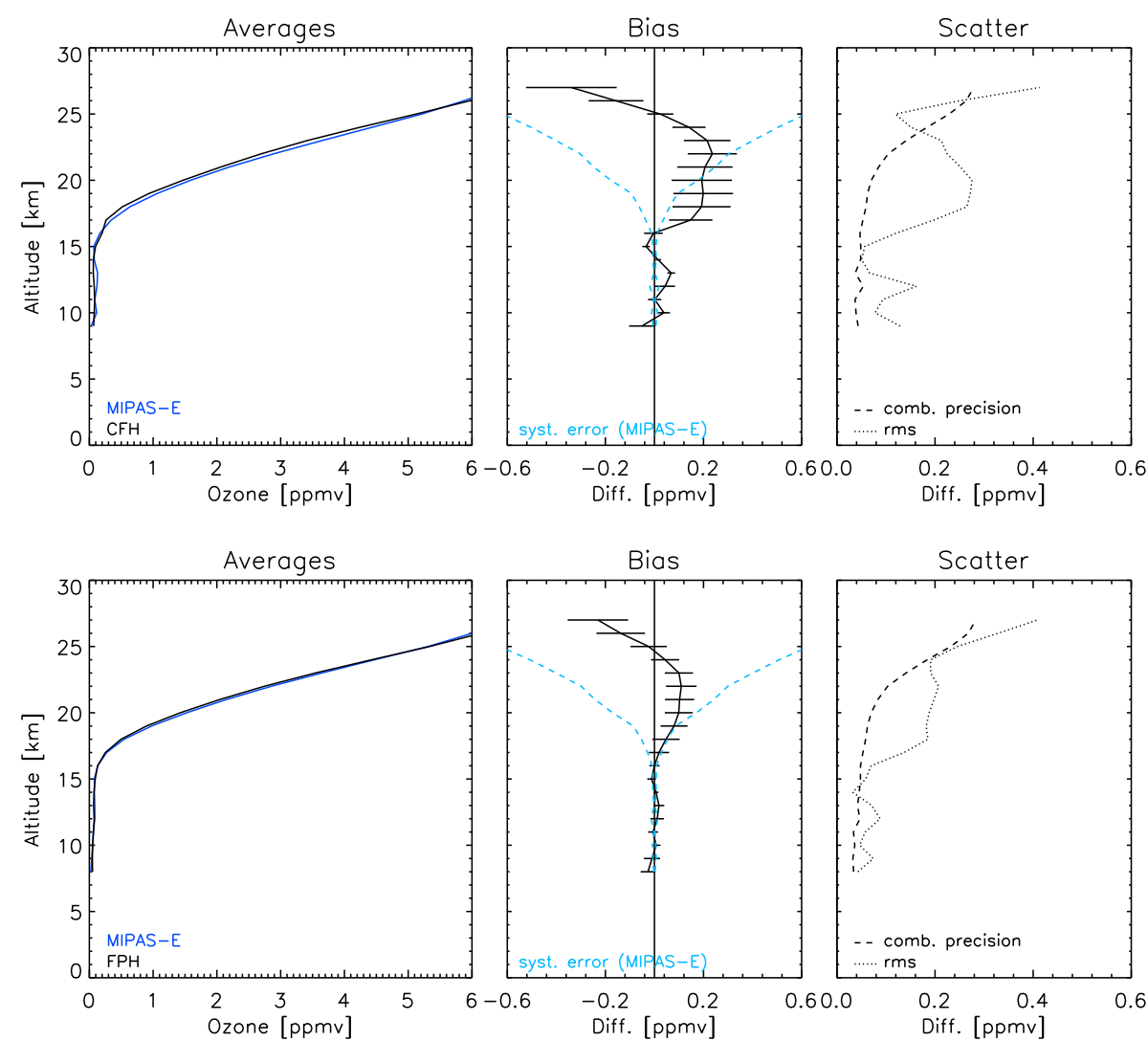

Fig. 17. Same as Fig. 2, but for ozonesonde profiles recorded on flights with the CFH v3.20 (top row) and NOAA FPH (bottom row) frost point hygrometers. For a more detailed description see Fig. 2.

Leblanc et al. (2012b) showed that during the MOHAVE2009 campaign the TMF site was just at the edge of the subtropical jet stream, and a stratospheric intrusion was observed passing the TMF site on 20 October 2009, which both caused high natural variability in temperature, water vapor and ozone around the tropopause, even within a few hundred kilometers.

The current analysis confirms earlier MIPAS temperature validation work of an older and different MIPAS temperature data version by Wang et al. (2005), who also found a small overall bias in MIPAS temperature data. Similar to the current study, Wang et al. (2005) found also rather high bias-corrected root mean squares differences $(2.5$ to $3.5 \mathrm{~K}$ in their case); they assessed the contribution of natural variability to the overall bias-corrected root mean squares differences (rms) and found that more than $70 \%$ of the rms can be explained by natural variability within the coincidence radii. In contrast to these earlier findings, however, is the high bias below the tropopause/low bias above the tropopause which showed up in the present assessment.

The recent MIPAS temperatures (version V4O_T_204) were retrieved with a retrieval set-up which was different from the older one because it was adjusted to the lower spectral, but higher spatial resolution of MIPAS measurements since 2005. As a consequence of the comparisons to MOHAVE-2009 campaign data, we re-analysed the spectral ranges used within the temperature retrieval. This showed that one small spectral window used for the retrievals was contaminated by an ozone line, and was therefore sensitive to errors in the ozone climatology used. Test retrievals have demonstrated that the deviations around the tropopause almost disappear if ozone is joint-fitted within the temperature retrieval so that it no longer depends on the used climatology. MIPAS temperature retrievals from version V4O_T_205 onwards will therefore be performed with the improved retrieval set-up including ozone as a joint-fit parameter.

\subsection{Synopsis from all instruments: water vapor}

Between $13 \mathrm{~km}$ and $55 \mathrm{~km}$, the MIPAS water vapor mean profiles (see Fig. 19, middle panel) are within $\pm 10 \%$ of the profiles of the correlative measurements, except for the STROZ lidar, AIRS, and MkIV. The STROZ lidar instrument is known to have a high bias of up to $20 \%$ above $12 \mathrm{~km}$ (see Sect. 3.1.1 and Leblanc et al., 2011) which explains the low bias of MIPAS versus STROZ. The discrepancy versus AIRS 

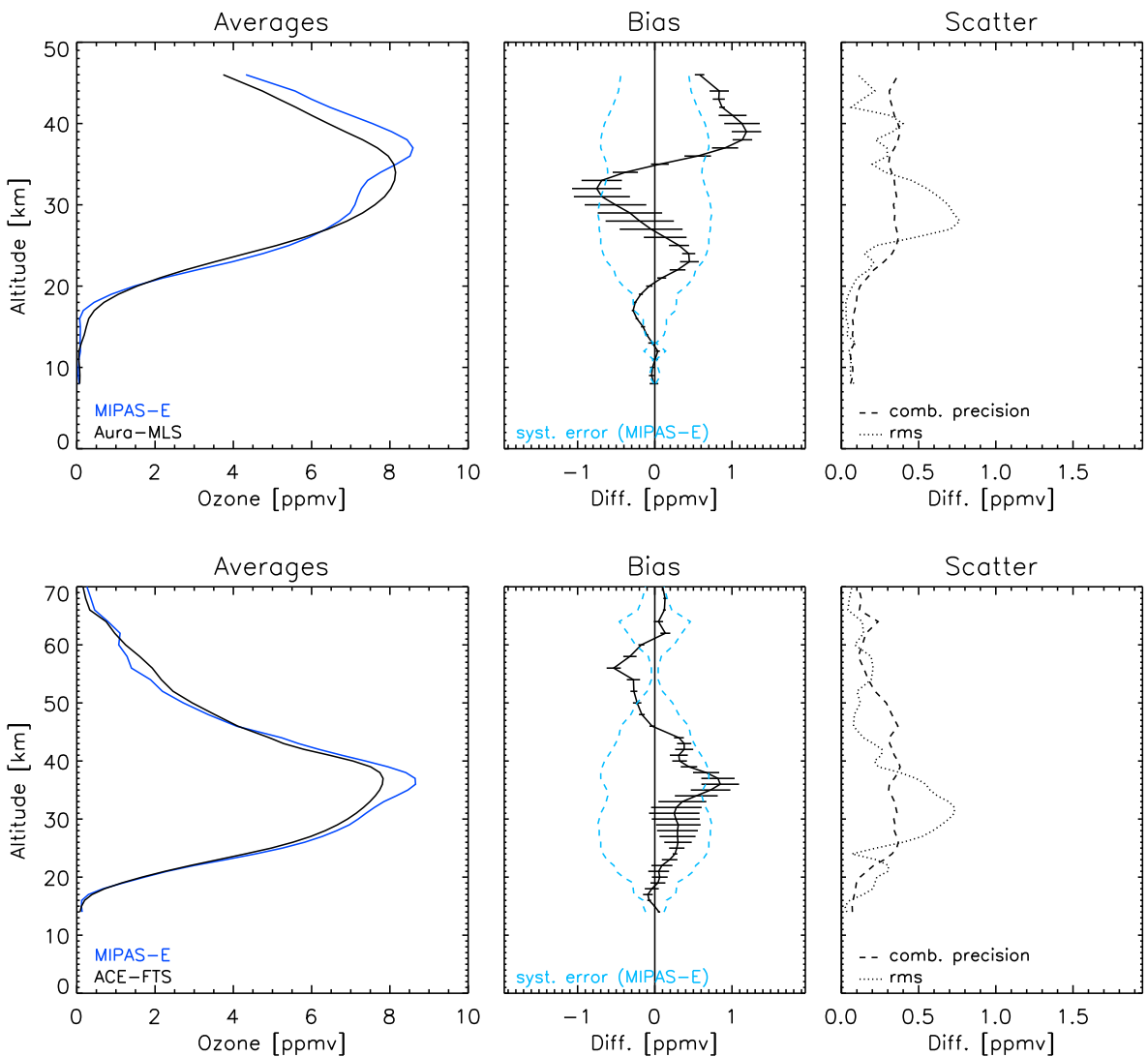

Fig. 18. Same as Fig. 2, but for Aura/MLS (top row) and ACE-FTS (bottom row) ozone profiles. For a more detailed description see Fig. 2.

is in the uppermost data point only which is around $100 \mathrm{hPa}$, and therefore at the edge of the sensitivity of the AIRS instrument; for this reason this discrepancy should be taken with some caution. The discrepancy versus MkIV is not in agreement with former MkIV validation efforts (Schneider et al., 2010). The discrepancy between TMW and MIPAS around $25 \mathrm{~km}$ can be explained with the fact that TMW lidar data are valid up to $22 \mathrm{~km}$ only. The agreement with ACE-FTS and MLS is well within $10 \%$ all over the stratosphere. The microwave instruments WVMS and MIAWARA-C both agree with MIPAS within $\pm 10 \%$. Three out of the four stratospheric data sets point towards a tendency of MIPAS to be biased high up to $10 \%$ around $45 \mathrm{~km}$, while above $55 \mathrm{~km}$, MIPAS has a tendency to be too dry. Both biases are a wellexplained consequence of the current MIPAS retrieval set up of water vapor which ignores non-LTE effects in radiative transfer in the mesosphere. The bulge at $45 \mathrm{~km}$ has been shown to be caused by error propagation from above and as such a compensation effect of the too low water vapor values retrieved in the mesosphere. In the troposphere below $13 \mathrm{~km}$, no consistent picture could be achieved: while the frost point hygrometers and the TMW lidar point towards a high bias of MIPAS, STROZ and MkIV and, below $9 \mathrm{~km}$, ALVICE and TMW indicate that MIPAS is biased low.
The systematic errors of MIPAS, given by spectroscopic uncertainty and, above $40 \mathrm{~km}$, non-LTE effects, can in most cases very well explain the biases to the other instruments. In the stratosphere, the bias-corrected rms is often lower than the estimated combined precisions by a factor of 2 which hints towards a far too pessimistic precision estimate; in the troposphere and around the tropopause, high natural variability due to the vicinity to the subtropical jet stream may explain the larger rms compared to the precision estimates.

An earlier MIPAS water vapor version (V3O_H2O_13) has been validated by Milz et al. (2009); they found no significant bias and a confirmation of the precision estimate which is on the order of 5-10\%. In particular, in their comparison to MIAWARA measurements taken during a campaign in Northern Finland, they found a similar bulge in the differences, but even more pronounced, around $45 \mathrm{~km}$ (see Milz et al., 2009, their Fig. 16). Tropospheric water vapor data were not compared. The findings of the MOHAVE-2009 campaign are in good agreement with the previous findings by Milz et al. (2009), although the MIPAS observation mode was changed to lower spectral and higher spatial resolution in the meantime. This is a good confirmation that the current retrieval setup is in accordance with previous data versions. 

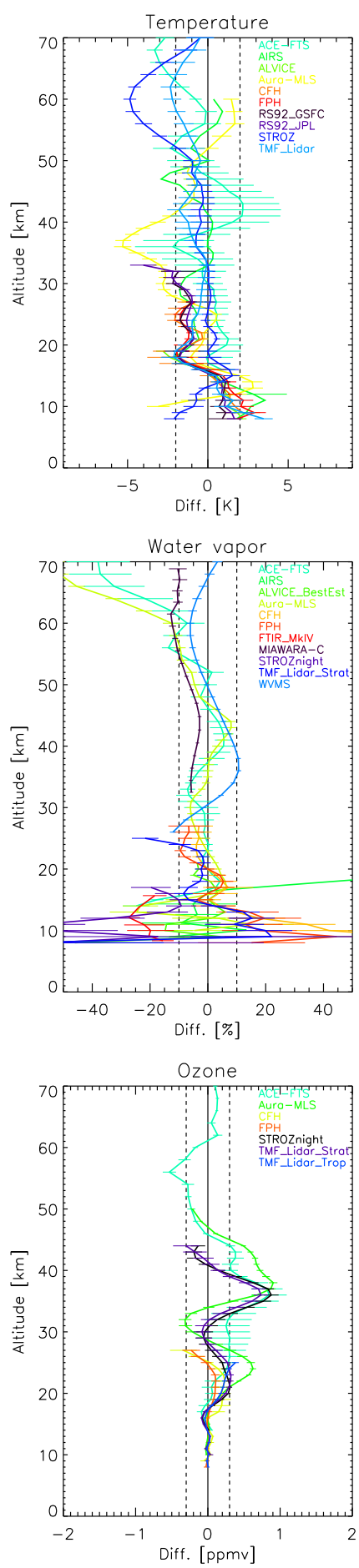

Fig. 19. Compilation of the mean differences between MIPAS and all instruments (MIPAS - correlative instrument) to which comparisons have been performed. Top: all mean temperature differences and their standard errors; middle: all mean water vapor differences and their standard errors (in percent relative to the reference profile); bottom: all mean ozone differences and their standard errors. Vertical lines are meant as guide for the eyes only.
In the next data version of MIPAS IMK/IAA water vapor we will include non-LTE modelling in the radiative transfer calculations for the retrievals according to García-Comas et al. (2012), which is expected to solve the problems at and above $45 \mathrm{~km}$.

\subsection{Synopsis from all instruments: ozone}

A synthesis of all ozone comparisons is shown in Fig. 19, bottom panel. The comparisons to all relevant instruments provided the following picture: MIPAS ozone profiles have a pronounced high bias at the upper edge of the stratospheric ozone VMR maximum around $37 \mathrm{~km}$, with differences reaching +0.9 ppmv in some cases (see Fig. 19, bottom panel). Between 50 and $60 \mathrm{~km}$, the only instrument for comparison is ACE-FTS. MIPAS is lower than ACE-FTS by up to -0.5 ppmv. However, a high bias of ACE-FTS ozone between 45 and $60 \mathrm{~km}$ is a known feature, although reduced in version 3 from the version 2.2 ozone update. Below $30 \mathrm{~km}$, the bias does not exceed \pm 0.3 ppmv except for the comparison with MLS. In the lower stratosphere, an oscillation with a maximum around $20 \mathrm{~km}$ and a minimum around $27 \mathrm{~km}$ has been identified in several difference profiles, which, however, does not exceed the estimated systematic errors of MIPAS ozone, and does not show up consistently in all comparisons.

A previous MIPAS ozone data version (V3O_O3_7) has been validated by Steck et al. (2007); in their comparisons, the bias between MIPAS ozone and other instruments was below \pm 0.3 ppmv, except for comparisons with HALOE and ground-based FTIR (see their Fig. 13). In particular, the mean comparison to lidars was better than 0.2 ppmv below $40 \mathrm{~km}$. Although not explicitly mentioned, the high bias found in the current data version around $37 \mathrm{~km}$ was present in some individual comparisons in version V3O_O3_7 as well (see their Fig. 5, top panel, or their Figs. 11 and 12).

During analyses performed as a consequence of the findings from the present validation study, the ozone peak around $37 \mathrm{~km}$ has been traced back to the handling of underlying continuum-like emissions in the spectral data. The continuum-like contribution is suspected to be caused by straylight from the Earth surface or the lowermost parts of the atmosphere, being scattered into the instrument's optics by internal parts. In the current retrieval set-up, atmospheric continuum extinction and emission due to aerosols and other atmospheric constituents are accounted for by fitting an optical depth profile up to $32 \mathrm{~km}$. A straylight-related radiance contribution at higher tangent altitudes can hence not be corrected. The straylight aspect is currently under further intense analysis; for MIPAS retrievals in the next future the continuum-like emission identified in the radiance spectra which leads to the ozone high bias around $37 \mathrm{~km}$ will be tackled as caused by an unidentified grey body which will be joint-fitted. Test retrievals have demonstrated that the high bias can be removed by extending the joint retrieval of an unidentified continuum extinction and emission up to $50 \mathrm{~km}$. 
Acknowledgements. The MOHAVE-2009 campaign was partly funded by the NASA Upper Atmosphere Research Program. The work by KIT was partly funded by the German Federal Ministry of Education and Research under contract no. 50EE0901. G. E. Nedoluha and R. M. Gomez were funded by NASA under the Upper Atmosphere Research Program and by the Naval Research Laboratory. M. García-Comas was supported by the CHOCOLATE project by ESA within the framework of the Changing Earth Science Network Initiative. AIRS and MLS data were obtained through the Goddard Earth Sciences Data and Information Services Center (http://daac.gsfc.nasa.gov/). The Atmospheric Chemistry Experiment (ACE), also known as SCISAT, is a Canadian-led mission mainly supported by the Canadian Space Agency (CSA) and the Natural Sciences and Engineering Research Council of Canada (NSERC).The authors acknowledge ESA for providing MIPAS L1b data. GS and TvC would like to thank F. Hase, KIT, for helpful discussions. The authors are grateful to two anonymous reviewers who helped to improve the manuscript with constructive and supportive comments.

Edited by: M. Van Roozendael

\section{References}

Bernath, P. F., McElroy, C. T., Abrams, M. C., Boone, C. D., Butler, M., Camy-Peyret, C., Carleer, M., Clerbaux, C., Coheur, P.F., Colin, R., DeCola, P., De Mazière, M., Drummond, J. R., Dufour, D., Evans, W. F. J., Fast, H., Fussen, D., Gilbert, K., Jennings, D. E., Llewellyn, E. J., Lowe, R. P., Mahieu, E., McConnell, J. C., McHugh, M., McLeod, S. D., Michaud, R., Midwinter, C., Nassar, R., Nichitiu, F., Nowlan, C., Rinsland, C. P., Rochon, Y. J., Rowlands, N., Semeniuk, K., Simon, P., Skelton, R., Sloan, J. J., Soucy, M.-A., Strong, K., Tremblay, P., Turnbull, D., Walker, K. A., Walkty, I., Wardle, D. A., Wehrle, V., Zander, R., and Zou, J.: Atmospheric Chemistry Experiment (ACE): Mission overview, Geophys. Res. Lett., 32, L15S01, doi:10.1029/2005GL022386, 2005.

Boone, C. D., Nassar, R., Walker, K. A., Rochon, Y., McLeod, S. D., Rinsland, C. P., and Bernath, P. F.: Retrievals for the atmospheric chemistry experiment Fourier- transform spectrometer, Appl. Opt., 44, 7218-7231, 2005.

Chahine, M.: Determination of the temperature profile in an atmosphere from its outgoing radiance, J. Opt. Sci. Am., 58, 16341637, 1968.

Chahine, M.: Remote sensing of cloudy atmospheres. 1. Multiple cloud formations, J. Atmos. Sci., 34, 744-757, 1977.

Chahine, M., Pagano, T., Aumann, H., Atlas, R., Barnet, C., Chen, L., Divakarla, M., Fetzer, E., Goldberg, M., Gautier, C., Granger, S., Irion, F. W., Kakar, R., Kalnay, E., Lambrigtsen, B., Lee, S., Marshall, J. L., McMillan, W., McMillin, L., Olsen, E. T., Revercomb, H., Rosenkranz, P., Smith, W., Staelin, D., Strow, L., Susskind, J., Tobin, D., and Wolf, W.: The Atmospheric Infrared Sounder (AIRS): improving weather forecasting and providing new insights into climate, B. Am. Meteorol. Soc., 87, 891-894, doi:10.1175/BAMS-87-7-891, 2006.

Chauhan, S., Höpfner, M., Stiller, G. P., von Clarmann, T., Funke, B., Glatthor, N., Grabowski, U., Linden, A., Kellmann, S., Milz, M., Steck, T., Fischer, H., Froidevaux, L., Lambert, A., Santee, M. L., Schwartz, M., Read, W. G., and Livesey, N. J.: MIPAS reduced spectral resolution UTLS-1 mode measurements of temperature, $\mathrm{O}_{3}, \mathrm{HNO}_{3}, \mathrm{~N}_{2} \mathrm{O}, \mathrm{H}_{2} \mathrm{O}$ and relative humidity over ice: retrievals and comparison to MLS, Atmos. Meas. Tech., 2, 337353, doi:10.5194/amt-2-337-2009, 2009.

Fetzer, E. J., Read, W. G., Waliser, D., Kahn, B. H., Tian, B., Vömel, H., Irion, F. W., Sun, H., Eldering, A., de la Torre Juarez, M., Jiang, J., and Dang, V.: Comparison of upper tropospheric water vapor observations from the Microwave Limb Sounder and Atmospheric Infrared Sounder, J. Geophys. Res., 113, D22110, doi:10.1029/2008JD010000, 2008.

Fischer, H., Birk, M., Blom, C., Carli, B., Carlotti, M., von Clarmann, T., Delbouille, L., Dudhia, A., Ehhalt, D., Endemann, M., Flaud, J. M., Gessner, R., Kleinert, A., Koopman, R., Langen, J., Lpez-Puertas, M., Mosner, P., Nett, H., Oelhaf, H., Perron, G., Remedios, J., Ridolfi, M., Stiller, G., and Zander, R.: MIPAS: an instrument for atmospheric and climate research, Atmos. Chem. Phys., 8, 2151-2188, doi:10.5194/acp-8-2151-2008, 2008.

Froidevaux, L., Jiang, Y., Lambert, A., Livesey, N., Read, W., Waters, J., Browell, E., Hair, J., Avery, M., McGee, T., Twigg, L., Sumnicht, G., Jucks, K., Margitan, J., Sen, B., Stachnik, R., Toon, G., Bernath, P., Boone, C., Walker, K., Filipiak, M., Harwood, R., Fuller, R., Manney, G., Schwartz, M., Daffer, W., Drouin, B., Cofield, R., Cuddy, D., Jarnot, R., Knosp, B., Perun, V., Snyder, W., Stek, P., Thurstans, R., and Wagner, P.: Validation of Aura Microwave Limb Sounder stratospheric ozone measurements, J. Geophys. Res., 113, D15S20, doi:10.1029/2007JD008771, 2008.

Gettelman, A., Weinstock, E., Fetzer, E., Irion, F., Eldering, A., Richard, E., Rosenlof, K., Thompson, T., Pittman, J., Webster, C., and Herman, R.: Validation of Aqua satellite data in the upper troposphere and lower stratosphere with insitu aircraft instruments, Geophys. Res. Lett., 31, L22107, doi:10.1029/2004GL020730, 2004.

García-Comas, M., Lopez-Puertas, M., Funke, B., BermejoPantaleon, D., Stiller, G., Grabowski, U., von Clarmann, T., and Lossow, S.: MIPAS non-LTE retrievals of water vapor in the middle atmosphere, in preparation, 2012.

Gil-López, S.: Determinación del ozono atmosférico de las medidas de MIPAS, Ph.D. thesis, University of Granada, Spain, 2006.

Glatthor, N., von Clarmann, T., Fischer, H., Funke, B., Grabowski, U., Höpfner, M., Kellmann, S., Kiefer, M., Linden, A., Milz, M., Steck, T., Stiller, G. P., Mengistu Tsidu, G., and Wang, D. Y.: Mixing processes during the Antarctic vortex split in September/October 2002 as inferred from source gas and ozone distributions from ENVISAT-MIPAS, J. Atmos. Sci., 62, 787-800, 2005.

Glatthor, N., von Clarmann, T., Fischer, H., Funke, B., GilLópez, S., Grabowski, U., Höpfner, M., Kellmann, S., Linden, A., López-Puertas, M., Mengistu Tsidu, G., Milz, M., Steck, T., Stiller, G. P., and Wang, D.-Y.: Retrieval of stratospheric ozone profiles from MIPAS/ENVISAT limb emission spectra: a sensitivity study, Atmos. Chem. Phys., 6, 2767-2781, doi:10.5194/acp-6-2767-2006, 2006.

Hagan, D., Webster, C., Farmer, C., May, R., Herman, R., Weinstock, E., Christensen, L., Lait, L. R., and Newman, P. A.: Validating AIRS upper atmosphere water vapor retrievals using aircraft and balloon in situ measurements, Geophys. Res. Lett., 31, L21103, doi:10.1029/2004GL020302, 2004.

Hauchecorne, A., Godin, S., Marchand, M., Heese, B., and 
Souprayen, C.: Quantification of the transport of chemical constituents from the polar vortex to midlatitudes in the lower stratosphere using the high-resolution advection model MIMOSA and effective diffusivity, J. Geophys. Res., 107, 8289, doi:10.1029/2001JD000491, 2002.

Hurst, D. F., Oltmans, S., Vömel, H., Rosenlof, K., Davis, S., Ray, E., Hall, E., and Jordan, A.: Stratospheric water vapor trends over Boulder, Colorado: Analysis of the 30 year Boulder record, J. Geophys. Res., 116, D02306, doi:10.1029/2010JD015065, 2011a.

Hurst, D. F., Hall, E. G., Jordan, A. F., Miloshevich, L. M., Whiteman, D. N., Leblanc, T., Walsh, D., Vömel, H., and Oltmans, S. J.: Comparisons of temperature, pressure and humidity measurements by balloon-borne radiosondes and frost point hygrometers during MOHAVE-2009, Atmos. Meas. Tech., 4, 2777-2793, doi:10.5194/amt-4-2777-2011, 2011 b.

Komhyr, W. D.: Electrochemical Concentration Cells for Gas Analysis, Ann. Geophys., 25, 203-210, 1969,

http://www.ann-geophys.net/25/203/1969/.

Komhyr, W. D., Barnes, R. A., Brothers, G. B., Lathrop, J. A., and Opperman, D. P.: Electrochemical concentration cell ozonesonde performance evaluation during STOIC 1989, J. Geophys. Res., 100, 9231-9244, doi:10.1029/94JD02175, 1995.

Lambert, A., Read, W. G., Livesey, N. J., Santee, M. L., Manney, G. L., Froidevaux, L., Wu, D. L., Schwartz, M. J., Pumphrey, H. C., Jimenez, C., Nedoluha, G. E., Cofield, R. E., Cuddy, D. T., Daffer, W. H., Drouin, B. J., Fuller, R. A., Jarnot, R. F., Knosp, B. W., Pickett, H. M., Perun, V. S., Snyder, W. V., Stek, P. C., Thurstans, R. P., Wagner, P. A., Waters, J. W., Jucks, K. W., Toon, G. C., Stachnik, R. A., Bernath, P. F., Boone, C. D., Walker, K. A., Urban, J., Murtagh, D., Elkins, J. W., and Atlas, E.: Validation of the Aura Microwave Limb Sounder middle atmosphere water vapor and nitrous oxide measurements, J. Geophys. Res., 112, D24S36, doi:10.1029/2007JD008724, 2007.

Leblanc, T., McDermid, I. S., and Aspey, R. A.: First-Year Operation of a New Water Vapor Raman Lidar at the JPL Table Mountain Facility, California, J. Atmos. Ocean. Technol., 25, 14541462, 2008.

Leblanc, T., Walsh, T. D., McDermid, I. S., Toon, G. C., Blavier, J.-F., Haines, B., Read, W. G., Herman, B., Fetzer, E., Sander, S., Pongetti, T., Whiteman, D. N., McGee, T. G., Twigg, L., Sumnicht, G., Venable, D., Calhoun, M., Dirisu, A., Hurst, D., Jordan, A., Hall, E., Miloshevich, L., Vömel, H., Straub, C., Kampfer, N., Nedoluha, G. E., Gomez, R. M., Holub, K., Gutman, S., Braun, J., Vanhove, T., Stiller, G., and Hauchecorne, A.: Measurements of Humidity in the Atmosphere and Validation Experiments (MOHAVE)-2009: overview of campaign operations and results, Atmos. Meas. Tech., 4, 2579-2605, doi:10.5194/amt-4-2579-2011, 2011.

Leblanc, T., McDermid, I. S., and Walsh, T. D.: Ground-based water vapor raman lidar measurements up to the upper troposphere and lower stratosphere for long-term monitoring, Atmos. Meas. Tech., 5, 17-36, doi:10.5194/amt-5-17-2012, 2012a.

Leblanc, T., Hauchecorne, A., Walsh, T., and McDermid, I.: Simultaneous Ozone and Water Vapor Lidar Observations and Modeling of a Stratospheric Intrusion during the MOHAVE-2009 Campaign, J. Geophys. Res., 116, submitted, 2012b.

Livesey, N. J., Filipak, M. J., Froidevaux, L., Read, W. G., Lambert, A., Santee, M. L., Jiang, J. H., Pumphrey, H. C., Wa- ters, J. W., Cofield, R. E., Cuddy, D. T., Daffer, W. H., Drouin, B. J., Fuller, R. A., Jarnot, R. F., Jiang, Y. B., Knosp, B. W., Li, Q. B., Perun, V. S., Schwartz, M. J., Snyder, W. V., Stek, P. C., Thurstans, R. P., Wagner, P. A., Avery, M., Browell, E. V., Cammas, J.-P., Christensen, L. E., Diskin, G. S., Gao, R.-S., Jost, H.-J., Loewenstein, M., Lopez, J. D., Nedelec, P., Osterman, G. B., Sachse, G. W., and Webster, C. R.: Validation of Aura Microwave Limb Sounder $\mathrm{O}_{3}$ and $\mathrm{CO}$ observations in the upper troposphere and lower stratosphere, J. Geophys. Res., 113, D15S02, doi:10.1029/2007JD008805, 2008.

López-Puertas, M. and Taylor, F. W.: Non-LTE radiative transfer in the Atmosphere, World Scientific Pub., Singapore, 2001.

Luers, J.: Temperature Error of the Vaisala RS90 Radiosonde, J. Atmos. Ocean. Technol., 14, 1520-1532, 1997.

McGee, T., Whiteman, D., Ferrare, R., Butler, J., and Burris, J. F.: STROZ LITE - STRatospheric OZone Lidar Trailer Experiment, Opt. Eng., 30, 31-39, 1991.

McGee, T., Gross, M., Singh, U., Butler, J., and Kimvilakani, P.: Improved Stratospheric Ozone Lidar, Opt. Eng., 34, 1421-1430, 1995.

McGee, T. J., Twigg, L., and Sumnicht, G.: STROZ Measurments during MOHAVE-2009, Atmos. Meas. Techn., 5, in preparation, 2012.

Milz, M., von Clarmann, T., Fischer, H., Glatthor, N., Grabowski, U., Höpfner, M., Kellmann, S., Kiefer, M., Linden, A., Mengistu Tsidu, G., Steck, T., Stiller, G. P., Funke, B., López-Puertas, M., and Koukouli, M. E.: Water Vapor Distributions Measured with the Michelson Interferometer for Passive Atmospheric Sounding on board Envisat (MIPAS/Envisat), J. Geophys. Res., 110, D24307, doi:10.1029/2005JD005973, 2005.

Milz, M., Clarmann, T. v., Bernath, P., Boone, C., Buehler, S. A., Chauhan, S., Deuber, B., Feist, D. G., Funke, B., Glatthor, N., Grabowski, U., Griesfeller, A., Haefele, A., Höpfner, M., Kmpfer, N., Kellmann, S., Linden, A., Mller, S., Nakajima, H., Oelhaf, H., Remsberg, E., Rohs, S., Russell III, J. M., Schiller, C., Stiller, G. P., Sugita, T., Tanaka, T., Vömel, H., Walker, K., Wetzel, G., Yokota, T., Yushkov, V., and Zhang, G.: Validation of water vapour profiles (version 13) retrieved by the IMK/IAA scientific retrieval processor based on full resolution spectra measured by MIPAS on board Envisat, Atmos. Meas. Tech., 2, 379399, doi:10.5194/amt-2-379-2009, 2009.

Nedoluha, G., Gomez, R., Hicks, B., Helmboldt, J., Bevilacqua, R., and Lambert, A.: Ground-based microwave measurements of water vapor from the midstratosphere to the mesosphere, J. Geophys. Res., 116, D02309, doi:10.1029/2010JD014728, 2011.

Oltmans, S. J., Vömel, H., Hofmann, D. J., Rosenlof, K. H., and Kley, D.: The increase in stratospheric water vapor from ballooneborne, frostpoint hygrometer measurements at Washington, D.C., and Boulder, Colorado, Geophys. Res. Lett., 27, 3453 3456, 2000.

Raspollini, P., Belotti, C., Burgess, A., Carli, B., Carlotti, M., Ceccherini, S., Dinelli, B. M., Dudhia, A., Flaud, J.-M., Funke, B. Höpfner, M., López-Puertas, M., Payne, V., Piccolo, C., Remedios, J. J., Ridolfi, M., and Spang, R.: MIPAS level 2 operational analysis, Atmos. Chem. Phys., 6, 5605-5630, doi:10.5194/acp6-5605-2006, 2006.

Read, W., Lambert, A., Bacmeister, J., Cofield, R., Christensen, L., Cuddy, D., Daffer, W., Drouin, B., Fetzer, E., Froidevaux, L., Fuller, R., Herman, R., Jarnot, R., Jiang, J., Jiang, Y., Kelly, 
K., Knosp, B., Pumphrey, H., Rosenlof, K., Sabounchi, X., Santee, M., Schwartz, M., Snyder, W., Stek, P., Su, H., Takacs, L., Thurstans, R., Vömel, H., Wagner, P., Waters, J., Webster, C., Weinstock, E., and Wu, D.: Aura Microwave Limb Sounder upper tropospheric and lower stratospheric $\mathrm{H}_{2} \mathrm{O}$ and relative humidity with respect to ice validation, J. Geophys. Res., 112, D24S35, doi:10.1029/2007JD008752, 2007.

Ridolfi, M., Carli, B., Carlotti, M., von Clarmann, T., Dinelli, B., Dudhia, A., Flaud, J.-M., Höpfner, M., Morris, P. E., Raspollini, P., Stiller, G., and Wells, R. J.: Optimized Forward and Retrieval Scheme for MIPAS Near-Real-Time Data Processing, Appl. Opt., 39, 1323-1340, 2000.

Rodgers, C. D.: Inverse Methods for Atmospheric Sounding: Theory and Practice, Vol. 2 of Series on Atmospheric, Oceanic and Planetary Physics, edited by: Taylor, F. W., World Scientific, 2000.

Schneider, M., Toon, G. C., Blavier, J.-F., Hase, F., and Leblanc, T.: $\mathrm{H}_{2} \mathrm{O}$ and $\Delta D$ profiles remotely-sensed from ground in different spectral infrared regions, Atmos. Meas. Tech., 3, 1599-1613, doi:10.5194/amt-3-1599-2010, 2010.

Schoeberl, M. R., Duncan, B. N., Douglass, A. R., Waters, J., Livesey, N., Read, W., and Filipiak, M.: The carbon monoxide tape recorder, Geophys. Res. Lett., 33, L12811, doi:10.1029/2006GL026178, 2006.

Schwartz, M., Lambert, A., Manney, G., Read, W., Livesey, N., Froidevaux, L., Ao, C., Bernath, P., Boone, C., Cofield, R., Daffer, W., Drouin, B., Fetzer, E., Fuller, R., Jarnot, R., Jiang, J., Jiang, Y., Knosp, B., Kruger, K., Li, J.-L., Mlynczak, M., Pawson, S., Russell, J., Santee, M., Snyder, W., Stek, P., Thurstans, R., Tompkins, A., Wagner, P., Walker, K., Waters, J., and Wu, D.: Validation of the Aura Microwave Limb Sounder Temperature and Geopotential Height Measurements, J. Geophys. Res., 113, D15S11, doi:10.1029/2007JD008783, 2008.

Steck, T., von Clarmann, T., Fischer, H., Funke, B., Glatthor, N., Grabowski, U., Höpfner, M., Kellmann, S., Kiefer, M., Linden, A., Milz, M., Stiller, G. P., Wang, D. Y., Allaart, M., Blumenstock, Th., von der Gathen, P., Hansen, G., Hase, F., Hochschild, G., Kopp, G., Kyrö, E., Oelhaf, H., Raffalski, U., Redondas Marrero, A., Remsberg, E., Russell III, J., Stebel, K., Steinbrecht, W., Wetzel, G., Yela, M., and Zhang, G.: Bias determination and precision validation of ozone profiles from MIPAS-Envisat retrieved with the IMK-IAA processor, Atmos. Chem. Phys., 7, 3639-3662, doi:10.5194/acp-7-3639-2007, 2007.

Stiller, G. P., von Clarmann, T., Funke, B., Glatthor, N., Hase, F., Höpfner, M., and Linden, A.: Sensitivity of trace gas abundances retrievals from infrared limb emission spectra to simplifying approximations in radiative transfer modelling, J. Quant. Spectrosc. Ra., 72, 249-280, 2002.

Straub, C., Murk, A., and Kämpfer, N.: MIAWARA-C, a new ground based water vapor radiometer for measurement campaigns, Atmos. Meas. Tech., 3, 1271-1285, doi:10.5194/amt-31271-2010, 2010.

Susskind, J., Barnet, C., and Blaisdell, J.: Retrieval of Atmospheric and Surface Parameters from AIRS/AMSU/HSB Data in the Presence of Clouds, IEEE Trans. Geosci. Remote Sens., 41, 390-409, 2003.

Susskind, J., Barnet, C., Blaisdell, J., Iredell, L., Keita, F., Kouvaris, L., Molnar, G., and Chahine, M.: Accuracy of geophysical parameters derived from Atmospheric Infrared Sounder/Advanced
Microwave Sounding Unit as a function of fractional cloud cover, J. Geophys. Res., 111, D09S17, doi:10.1029/2005JD006272, 2006.

Tobin, D., Revercomb, H., Knuteson, R., Lesht, B., Strow, L., Hannon, S., Feltz, W., Moy, L., Fetzer, E., and Cress, T.: Atmospheric Radiation Measurement site atmospheric state best estimates for Atmospheric Infrared Sounder temperature and water vapor retrieval validation, J. Geophys. Res., 111, D09S14, doi:10.1029/2005JD006103, 2006.

Toon, G. C.: The JPL MkIV Interferometer, Opt. Photonics News, 2, 19-21, 1991.

Vömel, H., David, D., and Smith, K.: Accuracy of tropospheric and stratospheric water vapor measurements by the cryogenic frost point hygrometer: Instrumental details and observations, J. Geophys. Res., 112, D08305, doi:10.1029/2006JD007224, 2007.

von Clarmann, T.: Validation of remotely sensed profiles of atmospheric state variables: strategies and terminology, Atmos. Chem. Phys., 6, 4311-4320, doi:10.5194/acp-6-4311-2006, 2006.

von Clarmann, T., Dudhia, A., Edwards, D. P., Funke, B., Höpfner, M., Kerridge, B., Kostsov, V., Linden, A., López-Puertas, M., and Timofeyev, Y. M.: Intercomparison of radiative transfer codes under non-local thermodynamic equilibrium conditions, $\mathrm{J}$. Geophys. Res., 107, 4631, doi:10.1029/2001JD001551, 2002.

von Clarmann, T., Ceccherini, S., Doicu, A., Dudhia, A., Funke, B., Grabowski, U., Hilgers, S., Jay, V., Linden, A., LópezPuertas, M., Martín-Torres, F.-J., Payne, V., Reburn, J., Ridolfi, M., Schreier, F., Schwarz, G., Siddans, R., and Steck, T.: A blind test retrieval experiment for infrared limb emission spectrometry, J. Geophys. Res., 108, 4746, doi:10.1029/2003JD003835, 2003a.

von Clarmann, T., Glatthor, N., Grabowski, U., Höpfner, M., Kellmann, S., Kiefer, M., Linden, A., Mengistu Tsidu, G., Milz, M., Steck, T., Stiller, G. P., Wang, D. Y., Fischer, H., Funke, B., Gil-López, S., and López-Puertas, M.: Retrieval of temperature and tangent altitude pointing from limb emission spectra recorded from space by the Michelson Interferometer for Passive Atmospheric Sounding (MIPAS), J. Geophys. Res., 108, 4736, doi:10.1029/2003JD003602, 2003b.

von Clarmann, T., Höpfner, M., Funke, B., López-Puertas, M., Dudhia, A., Jay, V., Schreier, F., Ridolfi, M., Ceccherini, S., Kerridge, B. J., Reburn, J., and Siddans, R.: Modelling of atmospheric mid-infrared radiative transfer: the AMIL2DA algorithm intercomparison experiment, J. Quant. Spectrosc. Ra., 78, 381-407, doi:10.1016/S0022-4073(02)00262-5, 2003c.

von Clarmann, T., Höpfner, M., Kellmann, S., Linden, A., Chauhan, S., Funke, B., Grabowski, U., Glatthor, N., Kiefer, M., Schieferdecker, T., Stiller, G. P., and Versick, S.: Retrieval of temperature, $\mathrm{H}_{2} \mathrm{O}, \mathrm{O}_{3}, \mathrm{HNO}_{3}, \mathrm{CH}_{4}, \mathrm{~N}_{2} \mathrm{O}, \mathrm{ClONO}_{2}$ and $\mathrm{ClO}$ from MIPAS reduced resolution nominal mode limb emission measurements, Atmos. Meas. Tech., 2, 159-175, doi:10.5194/amt-2-1592009, 2009.

Wang, D.-Y., Stiller, G. P., von Clarmann H. Fischer, T., LópezPuertas, M., Funke, B., Glatthor, N., Grabowski, U., Höpfner, M., Kellmann, S., Kiefer, M., Linden, A., Mengistu Tsidu, G., Milz, M., Steck, T., Jiang, J. H., Ao, C. O., Manney, G., Hocke, K., Wu, D. L., Romans, L. J., Wickert, J., and Schmidt, T.: Cross-validation of MIPAS/ENVISAT and GPS-RO/CHAMP temperature profiles, J. Geophys. Res., 109, 
D19311, doi:10.1029/2004JD004963, 2004.

Wang, D. Y., von Clarmann, T., Fischer, H., Funke, B., Gil-López, S., Glatthor, N., Grabowski, U., Höpfner, M., Kaufmann, M., Kellmann, S., Kiefer, M., Koukouli, M. E., Linden, A., LópezPuertas, M., Mengistu Tsidu, G., Milz, M., Steck, T., Stiller, G. P., Simmons, A. J., Dethof, A., Swinbank, R., Marquardt, C., Jiang, J. H., Romans, L. J., Wickert, J., Schmidt, T., Russell III, J., and Remsberg, E.: Validation of stratospheric temperatures measured by Michelson Interferometer for Passive Atmospheric Sounding MIPAS on Envisat, J. Geophys. Res., 110, D08301, doi:10.1029/2004JD005342, 2005.
Whiteman, D., Cadirola, M., Venable, D., Calhoun, M., Miloshevich, L., Vermeesch, K., Twigg, L., Dirisu, A., Hurst, D., Hall, E., Jordan, A., and Vömel, H.: Correction technique for raman water vapor lidar signal dependent bias and suitability for water vapor trend monitoring in the upper troposphere, Atmos. Meas. Techn. Discuss., 4, 7337-7403, doi:10.5194/amtd-4-7337-2011, 2011. 